Universidade de Brasília - UnB

Instituto de Ciências Humanas - IH

Departamento de Geografia - GEA

Programa de Pós-Graduação em Geografia

UNIVERSIDADE DE BRASÍLIA

PÓS-GRADUAÇÃO EM GEOGRAFIA

MONITORAMENTO DE QUEIMADAS NO SUDOESTE DO PARÁ, A PARTIR DE SÉRIES TEMPORAIS DO SENSOR MODIS

Níckolas Castro Santana

Dissertação de Mestrado

Brasília-DF, Fevereiro de 2016. 
Instituto de Ciências Humanas - IH

Departamento de Geografia - GEA

Programa de Pós-Graduação em Geografia

UNIVERSIDADE DE BRASÍLIA

PÓS-GRADUAÇÃO EM GEOGRAFIA

\section{MONITORAMENTO DE QUEIMADAS NO SUDOESTE DO PARÁ, A PARTIR DE} SÉRIES TEMPORAIS DO SENSOR MODIS

Níckolas Castro Santana

Orientador: Osmar Abílio de Carvalho Júnior

Dissertação de Mestrado

Brasília-DF, Fevereiro de 2016. 


\title{
MONITORAMENTO DE QUEIMADAS NO SUDOESTE DO PARÁ, A PARTIR DE SÉRIES TEMPORAIS DO SENSOR MODIS
}

\author{
Níckolas Castro Santana
}

Dissertação de Mestrado submetida ao Departamento de Geografia da Universidade de Brasília, como parte dos requisitos necessários para a obtenção do Grau de Mestre em Geografia, área de concentração Gestão Ambiental e Territorial, opção Acadêmica.

Aprovado por:

Osmar Abílio de Carvalho Júnior, Doutor (Geografia - UnB)

(Orientador)

Potira Meirelles Hermuche, Doutora (Geografia - UnB)

(Examinador Interno)

Marcelo Brilhante de Medeiros, Doutor (EMBRAPA - Recursos Genéticos e Biotecnologia) (Examinador Externo)

Nilton Correia da Silva, Doutor (Engenharia - UnB/Gama)

(Examinador Externo/Suplente)

Brasília-DF, Fevereiro de 2016. 


\section{SANTANA, NÍCKOLAS CASTRO}

Monitoramento de queimadas no sudoeste do Pará, a partir de séries temporais do sensor MODIS, 63 p., (UnB-IH-GEA, Mestre, Gestão Ambiental e Territorial, 2016).

Dissertação de Mestrado - Universidade de Brasília. Departamento de Geografia.

1. Áreas Queimadas

3. Sensoriamento Remoto

I. UnB-IH-GEA
2. Séries Temporais

4. Floresta Amazônica

É concedida à Universidade de Brasília permissão para reproduzir cópias desta dissertação e emprestar ou vender tais cópias somente para propósitos acadêmicos e científicos. O autor reserva outros direitos de publicação e nenhuma parte desta dissertação de mestrado pode ser reproduzida sem a autorização por escrito do autor. 


\section{AGRADECIMENTOS}

A Deus por todas as bênçãos concedidas.

Aos meus pais Valdenise e José, pela educação, incentivos e por sempre me ensinar que a educação é a forma mais digna de construir meu futuro.

Ao Professor Dr. Osmar Abílio de Carvalho Júnior pelo incentivo e apoio nesta jornada.

Aos Professores do Departamento de Geografia da Universidade de Brasília pelos conhecimentos compartilhados.

Aos professores de Geografia da Graduação e Orientadores de Estágio pelo amor demonstrado pela Geografia e por todas as lições que ficarão para toda a vida.

Aos professores Dra. Potira Meirelles Hermuche e Dr. Nilton Correia da Silva pela participação e contribuições na banca desta dissertação.

Aos amigos conquistados ao longo destes anos de Mestrado, em especial os companheiros de laboratório, Sandro Nunes, Cristiane Batista, Verônica Moreira, Miriam Rodrigues, Marcus Fábio, Paulo Henrique, Marcos Pereira e Núbia Oliveira. Obrigado por todas as conversas e discussões enriquecedoras!

Ao Serviço Geológico dos Estados Unidos pela política de distribuição gratuita de suas imagens de Sensoriamento Remoto.

A CAPES pelo apoio financeiro para a conclusão desta pesquisa. 


\section{RESUMO}

As queimadas associadas à expansão da pecuária e agricultura têm se tornado um problema no bioma Amazônico, causando danos severos ao meio ambiente. Imagens de sensoriamento remoto têm sido amplamente utilizadas no monitoramento de queimadas na extensa Floresta Amazônica, porém há a necessidade de aprimoramentos metodológicos para uma detecção automatizada. Esta pesquisa tem como objetivo avaliar séries temporais MODIS para o mapeamento de áreas queimadas no município de Novo Progresso, Pará, e determinar suas ocorrência nos diferentes tipos de uso e cobertura da terra durante o período de 2000-2014. $\mathrm{Na}$ detecção de área queimada, os seguintes dados foram comparados: banda do infravermelho próximo e índices espectrais (NBR, NDVI e NBRT), considerando-se imagens diárias e produtos compostos de 8 dias. As séries temporais MODIS foram filtradas e normalizadas temporalmente para eliminar falsos eventos de queimadas. A determinação dos valores limites para a ocorrência de queimadas foi obtida a partir da comparação da série de imagens MODIS com classificações visuais de dados LANDSAT/TM e ETM+ usando o coeficiente Kappa. O melhor resultado alcançado considerou os seguintes fatores: banda de infravermelho próximo, imagens diárias e normalização pela média, obtendo o valor de coeficiente Kappa de 0,72 e Acurácia Geral de 99\%. As áreas desmatadas são as responsáveis por mais de $70 \%$ dos eventos de incêndios. As propriedades privadas apresentaram maior porcentagem de área queimada, enquanto as Reservas Ambientais Particulares e Terras Indígenas apresentaram as menores taxas. $\mathrm{O}$ resultado do método proposto foi melhor do que o disponível pelo produto de áreas queimadas (MCD45), mas ainda apresenta interferências de cobertura de nuvens que devem ser melhoradas em trabalhos futuros.

Palavras-chave: Áreas Queimadas, Séries Temporais, Sensoriamento Remoto, Floresta Amazônica. 


\begin{abstract}
Fires associated with the expansion of cattle ranching and agriculture has become a problem in the Amazon biome, causing severe environmental damages. Remote sensing images have been widely used in the fire monitoring on the extensive Amazon forest, but an accurate automated detection still need improvements. This research aims to evaluate MODIS time series spectral indices for mapping burned areas in the municipality of Novo Progresso, Para, and determine their occurrences in the different types of land use/land cover during the period 2000-2014. In burned area detection, the following data were compared: near-infrared band and spectral indices (NBR, NDVI and NBRT), considering daily images and 8-day composite products. MODIS time series were filtered and standardized temporally to eliminate false fire events. Threshold-value determination for the fire occurrences was obtained from the comparison of MODIS series with visual image classification of Landsat TM and ETM+ data using the Kappa coefficient. The best result considered the following factors: near-infrared band, daily data, and mean standardization, obtaining the Kappa coefficient value of 0.72 and Overall accuracy of $99 \%$. The deforested areas are responsible for more than $70 \%$ of fire events. Private properties showed a higher percentage of the burned area, while private and Indigenous Lands Environmental Reserves had the lowest rates. The result of the proposed method was better than the burned area product (MCD45), but still shows cloud cover interference that should be improved in future work.
\end{abstract}

Keywords: Burned Area, Time Series, Remote Sensing, Amazon Forest 


\section{SUMÁRIO}

1. INTRODUÇÃ

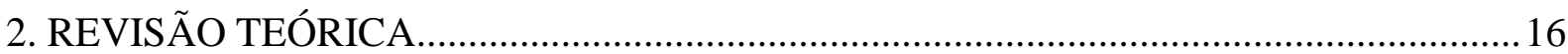

2.1 Efeitos das Queimadas e sua Distribuição nos Biomas Brasileiros...................................16

2.2 Monitoramento de Queimadas por Imagens Orbitais ..................................................... 18

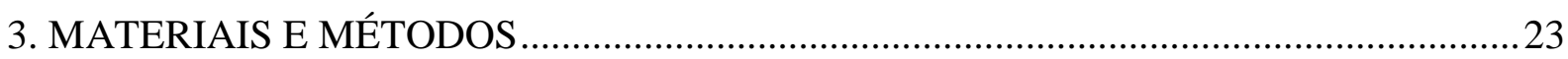

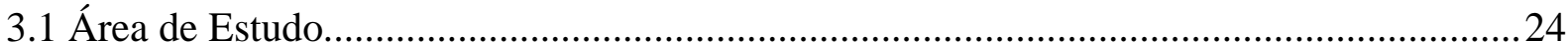

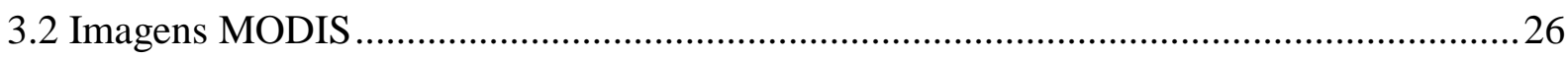

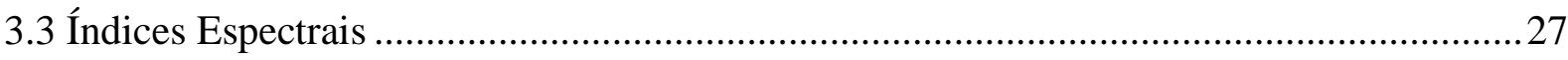

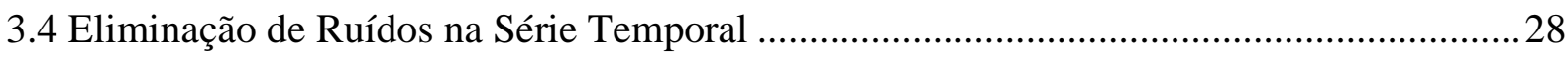

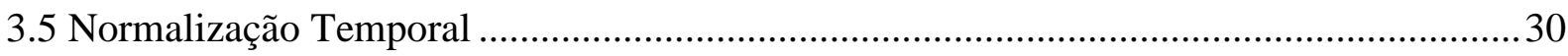

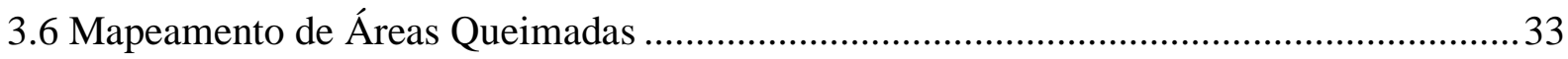

3.7 Análise de Acurácia e Comparação dos dados .....................................................................34

3.8 Análise dos eventos de fogo pela classe de uso e ocupação da terra..................................34

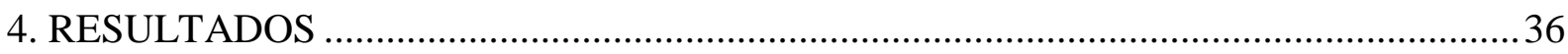

4.1 Determinação do Melhor Valor Limite para Detecção de Áreas Queimadas ....................36

4.2 Caracterização Temporal das Ocorrências de Queimadas .................................................37

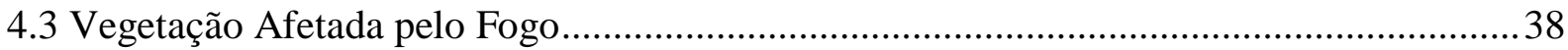

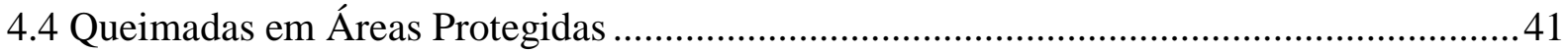

4.5 Validação do Mapeamento e Comparação de dados .........................................................42

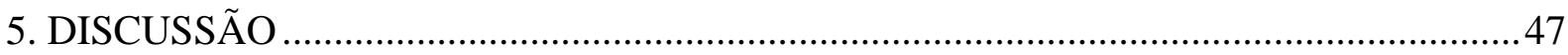

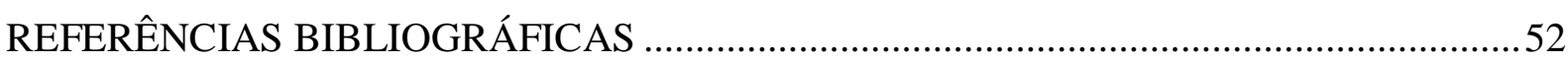




\section{LISTA DE FIGURAS}

Figura 1: Focos do Incêndio Anuais por Bioma Brasileiro. 17

Figura 2: Resposta Espectral de Vegetação Saudável e Vegetação Queimada.......................19

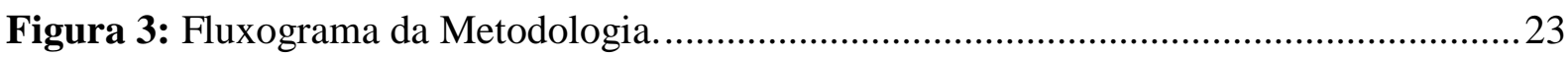

Figura 4: Área de Estudo, Categorias e Tipo de Cobertura da Terra....................................25

Figura 5: Exemplo de Filtragem da Série Temporal de Reflectância MODIS (Banda 2) em área de pastagem.

Figura 6: Separação de alvos queimados e não queimados. (a) Espectros refletidos no Infravermelho Próximo sem Normalização. (b) Espectros refletidos no Infravermelho Próximo com Normalização por média. 30

Figura 7: Exemplo de Alvos não Queimados no Canal do Infravermelho Próximo.

Figura 8: Exemplo de Alvos não Queimados no Canal do Infravermelho Próximo após Normalização.

Figura 9: Definição do valor limite para 2001. A partir do calculo do Coeficiente de Kappa para cada valor de pixel no Infravermelho Próximo é definido o valor com o melhor resultado.

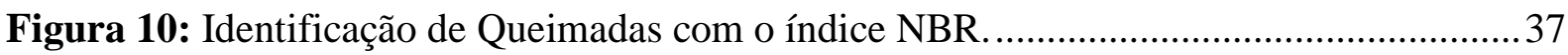

Figura 11: Área Queimada Anualmente (Junho a Novembro), Imagens MODIS Diárias. ....37

Figura 12: Área Queimada Anualmente: 2000 - 2014 ..........................................................39

Figura 13: Queimadas Anuais por Tipo de Gestão. ..............................................................41

Figura 14: Comparação do Mapeamento de Queimadas: Método Proposto, MCD45 e Landsat/TM.

Figura 15: Focos de Incêndio Ativos, Detectados por Satélite, Localizados em Pixels Queimados. 


\section{LISTA DE TABELAS}

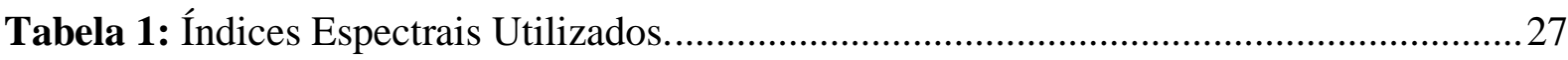

Tabela 2: Definição de Valor Limite para os diferentes métodos testados. ............................36

Tabela 3: Ocorrência de queimadas anuais por uso e cobertura da terra a partir de imagens MODIS diárias.

Tabela 4: Coeficiente de Kappa e Acurácia Geral do Mapeamento (Áreas Queimadas MODIS x Áreas Queimadas ETM+/TM).

Tabela 5: Coeficiente de Kappa e Acurácia Geral do Mapeamento (Áreas Queimadas MCD45 x Áreas Queimadas TM). .44

Tabela 6: Coeficiente Kappa e Acurácia Geral do Mapeamento (Áreas Queimadas MCD45 X Áreas Queimadas Método Proposto) 


\section{LISTA DE ABREVIATURAS E SIGLAS}

$\begin{array}{ll}\text { APA } & \text { Área de Proteção Ambiental } \\ \text { ATSR } & \text { Advanced Along Track Scanning Radiometer } \\ \text { AVHRR } & \text { Advanced Very High Resolution Radiometer } \\ \text { BAI } & \text { Burn Area Index } \\ \text { EOS } & \text { Earth Observing System } \\ \text { ERS } & \text { European Remote Sensing } \\ \text { ETM } & \text { Enhanced Thematic Mapper } \\ \text { FUNAI } & \text { Fundação Nacional do Índio } \\ \text { GEMI } & \text { Global Environmental Index }\end{array}$

GOES Geostationary Operational Environmental Satellite

IBAMA Instituto Brasileiro do Meio Ambiente e Recursos Naturais Renováveis

IBGE Instituto Brasileiro de Geografia e Estatística

ICMBio Instituto Chico Mendes de Conservação da Biodiversidade

IMAZON Instituto do Homem e Meio Ambiente da Amazônia

INCRA Instituto Nacional de Colonização e Reforma Agrária

INMET Instituto Brasileiro de Meteorologia

INPE Instituto Nacional de Pesquisas Espaciais

LANDSAT Land Remote Sensing Satellite

MCD45 MODIS/Terra+Aqua Burned Area Monthly Global 500m

METEOSAT Meterological Satellite

MODIS Moderate Resolution Imaging Spectroradiometer

MSG Meteosat Second Generation

NASA National Aeronautics and Space Administration

NBR Normalized Burn Ratio

NBRT Normalized Burn Ratio Thermal 
NDVI Normalized Difference Vegetation Index

NIR Near Infrared

NOAA National Oceanic and Atmospheric Administration

NPP National Polar-orbiting Partnership

PA Projeto de Assentamento Tradicional

PDS Projeto de Assentamento de Desenvolvimento Sustentável

SAVI Soil Adjusted Vegetation Index

SG Savitzky \& Golay

SIVAM Sistema de Vigilância da Amazônia

SPOT Satellite Pour l'Observation de la Terre

SWIR Shortwave Infrared

TM Thematic Mapper

TRMM Tropical Rainfall Measuring Mission 


\section{INTRODUÇÃO}

As queimadas desempenham um papel importante em diversos ecossistemas terrestres e têm sido utilizadas pelo homem para diversos fins, como no desflorestamento e manejo de pastagens e culturas (JOLLY, 2015). Entretanto, os seus principais efeitos são negativos, dentre eles a emissão de gases de efeito estufa (van der WERF et al., 2009; MIEVILLE et al., 2010), degradação florestal (COCHRANE \& LAURANCE, 2002), degradação do solo (ICE et al., 2004) e problemas de saúde humana (IGNOTTI, 2010; REDDINGTON et al., 2015).

A região Amazônica possui poucos registros de queimadas nos períodos anteriores a colonização, sendo principalmente relacionados aos eventos climáticos (SALDARRIAGA \& WEST, 1986; BUSH et al., 2008). Atualmente, vários estudos demonstram a correlação entre períodos de seca na Amazônia e os eventos de El Niño (MARENGO, 1992, 2004; RONCHAIL et al., 2002), Oscilação Multidecanal do Atlânticoe a Temperatura da água do mar do Atlântico (LI et al., 2006; MARENGO et al., 2008, LEWIS et al., 2011). Estes períodos de seca severa aumentam a mortalidade das árvores nas margens das florestas e o acúmulo de folhas secas (LAURANCE \& WILLIAMSON, 2001; PHILLIPS et al., 2010), que favorecem os eventos de fogo principalmente em floresta degradada (NEPSTAD et al., 2004, ALENCAR et al., 2006; ARAGÃO et al., 2007).

No entanto, ação humana potencializa os efeitos climáticos e consiste na principal causa dos eventos de queimadas na Floresta Amazônica, ocorrendo principalmente em áreas de desmatamento e manejo de agricultura e pastagens (MORTON et al., 2008; COCHRANE 2001; PIVELLO, 2011; SILVESTRINI et al., 2011). O fogo utilizado na pecuária e agricultura normalmente escapa para áreas florestais vizinhas, ocasionando incêndios de maiores proporções (CANO-CRESPO et al., 2015). Portanto, o uso e cobertura do solo condicionam os padrões de queimadas da floresta Amazônica, onde as Unidades de Conservação e as Terras Indígenas são importantes barreiras, enquanto as localidades com intenso desmatamento, fragmentação e presença de rodovias apresentam maior número de incêndios (NEPSTAD et al., 2001, 2006; COCHRANE \& LAURANCE, 2002).

A Amazônia apresenta alta vulnerabilidade a incêndios florestais devido aos seguintes fatores: a maioria das espécies não tolera eventos recorrentes de queimada, a matéria orgânica essencial para a manutenção dos processos ecológicos é incinerada, e ocorrem alterações na composição florística e estrutural da floresta (COCHRANE \& SCHULZE, 1999; CHUVIECO et al., 2014; NEPSTAD et al., 1999). A fragmentação da paisagem da Amazônia torna a floresta mais susceptível a eventos de fogo (ALENCAR et al., 2015). As queimadas 
na Amazônia estão concentradas ao longo do "arco do desmatamento", uma região crescente entre as bordas leste e sul da floresta com intensificação das ações antrópicas. Em comparação com florestas do interior da Amazônia, as do arco do desmatamento têm menor biomassa e clima mais seco, resultando em queimadas de maior proporção (RIGHI et al., 2009). Modelos dos efeitos de mudanças climáticas na Amazônia preveem a expansão de queimadas na região devido às secas mais frequentes e intensificação do uso do solo (SILVESTRINI, 2011; GUTIÉRREZ-VÉLEZ et al., 2014).

No monitoramento da Floresta Amazônia, com extensão total de 5,5 milhões de $\mathrm{km}^{2}$, torna-se necessário o emprego de dados de sensoriamento remoto devido a sua rapidez de obtenção e ampla cobertura da superfície terrestre. No entanto, os dados de sensores ópticos na região Amazônica ficam sujeitos a uma alta interferência de cobertura de nuvens e aerossóis dificultando o monitoramento dos focos de incêndio e área queimada. Na época de estiagem, onde há a possibilidade de aquisição de imagens com baixa cobertura de nuvens, a intensa atividade de queimadas e a consequente liberação de aerossóis dificultam a utilização dos métodos tradicionais de mapeamento baseados na faixa espectral do vermelho e infravermelho próximo (PEREIRA, 2003; LIBONATI et al., 2010). Desta forma, o emprego de sensores com alta resolução temporal, que possibilitam a aquisição de imagens com boa qualidade atmosférica, conciliados com os métodos estatísticos é essencial para o monitoramento de incêndios florestais (LENTILE et al., 2006; MOUILLOT et al., 2014; HUESCA et al., 2014).

Os estudos de fogo que utilizam técnicas de sensoriamento remoto podem ser subdivididos em duas abordagens: identificação de focos ativos de incêndios ou o mapeamento das áreas pós-fogo evidenciadas pela deposição de cinzas e carvão e pela modificação da estrutura e biomassa da vegetação. A detecção de focos ativos fornece informações a respeito do local e do momento da ocorrência do fogo, no entanto não permite a quantificação da área afetada pelos incêndios detectados (ROY et al., 2005; GIGLIO et al., 2009), uma vez que captura a emissão da energia do fogo ativo antes do que a área de atividade de fogo (GIGLIO et al., 2006a). Em contraposição, o mapeamento pós-fogo permite obter perímetro, área e estimativa de danos causados por incêndios florestais.

Entre os sensores com alta resolução temporal, o sensor MODIS tem se destacado no mapeamento de queimadas nos diferentes biomas terrestres (GIGLIO et al., 2009; BASTARRIKA et al., 2011; HARDTKE et al, 2015), oferecendo produtos em escala global de focos ativos de incêndio (KAUFMAN \& JUSTICE, 1998; JUSTICE et al. 2002a; GIGLIO et al., 2006a) e de áreas queimadas (GIGLIO et al., 2006b, 2009). O produto MODIS de 
anomalias termais (MOD14/MYD14) tem sido amplamente utilizado nos estudos de incêndios na Amazônia (e.g. MORTON et al., 2008; ARMENTERAS \& RETANA, 2012; FERNANDES et al., 2011). Piromal et al. (2008) avaliam o produto para a região Amazônica no norte do Estado do Mato Grosso e constatam que o método acertou 51,58\% do total de áreas queimadas, onde a maioria das áreas não detectadas ocorrem em áreas de pequena dimensão (tamanho médio de 38,74 ha). Além disso, os autores demonstram que o produto MOD14 superestima a quantidade de áreas queimadas considerando erroneamente áreas de solos expostos, florestas e outros tipos de coberturas da terra. O produto MODIS de área queimada (MCD45) também consiste em um importante dado de pesquisas de incêndio na Amazônia (e.g. FANIN \& van der WERF, 2015). No entanto, Cardozo et al., (2012) demonstram que esse produto para distintas datas apresentavam valores superiores a $90 \%$ de erros de omissão, que evidencia uma baixa confiabilidade para identificar áreas queimadas e a necessidade de novas pesquisas para o desenvolvimento de técnicas de detecção de áreas queimadas a partir de longas séries temporais.

Diferentes metodologias têm sido propostas para o mapeamento de áreas queimadas com base em imagens de satélite. O processamento mais amplamente utilizado para a detecção de áreas queimadas usando imagens bitemporais combina duas operações algébricas: (a) cálculo do índice espectral, sendo os mais utilizados o Normalized Burned Ratio (NBR) (KEY \& BENSON, 2006) e Normalized Difference Vegetation Index (NDVI) (ROUSE et al., 1974); e (b) diferença sazonal considerando as imagens dos índices pré- e pós-queimada, como por exemplo dNDVI (KASISCHKE et al., 1993) e dNBR (KEY \& BENSON, 2006). A inclusão de bandas termais no cálculo do índice NBR, também tem sido utilizada com o mesmo objetivo, o índice mais utilizado neste caso é o Normalized Burn Ratio Thermal (NBRT), que multiplica o valor de temperatura superficial com a banda do infravermelho de ondas curtas, melhorando a diferenciação de áreas queimadas e não queimadas (HOLDEN et al., 2005).

O procedimento de diferença sazonal tem sido aplicado para as imagens de séries temporais longas do sensor MODIS, no entanto apresenta um significativo aumento da relação sinal/ruído necessitando de aperfeiçoamentos metodológicos (LOBODA et al., 2007; VERAVERBEKE et al., 2010). Uma alternativa ao uso da diferença sazonal é o emprego da normalização de séries temporais usando os métodos z-score (média igual a zero e desvio padrão igual a 1) ou média (média igual a zero), que permitem destacar as áreas queimadas sem alterar a relação sinal/ruído (CARVALHO JÚNIOR et al., 2015). 
O presente trabalho possui como objetivo avaliar e comparar diferentes procedimentos de detecção de áreas queimadas no município de Novo Progresso, na região Amazônica, a partir de séries temporais MODIS, utilizando-se dos índices espectrais NDVI, NBR, NBRT, a banda do Infravermelho Próximo e métodos de normalização por Média e Z-Score. Além disso, buscou-se analisar a distribuição das áreas queimadas pelos tipos de uso e cobertura da terra. Os objetivos específicos da pesquisa foram:

- Analisar o resultado da metodologia aplicada em comparação com o produto global de mapeamento de áreas queimadas MCD45 e focos de incêndio ativos.

- Especificar os tipos de vegetação ou uso antrópico mais afetados pelos eventos de queimadas, a partir de dados de mapeamento da vegetação do IBGE.

- Quantificar o total de áreas queimadas por proprietário da terra a partir de dados de órgãos governamentais brasileiros.

- Caracterizar, espacial e temporalmente, as queimadas no município de Novo Progresso - PA, para a série histórica de 2000 a 2014. 


\section{REVISÃO TEÓRICA}

\subsection{Efeitos das Queimadas e sua Distribuição nos Biomas Brasileiros}

O fogo é um importante fator de transformação dos ecossistemas terrestres, variando a sua frequência e intensidade conforme as variáveis climáticas, tipos de vegetação e atividades antrópicas. Por exemplo, áreas desérticas são pouco afetadas pelo fogo devido à baixa disponibilidade de combustível e as florestas tropicais por causa das condições climáticas úmidas que dificultam a propagação do fogo. No entanto, as previsões apontam para um aumento dos impactos de fogo devido à influência do ser humano e a alteração do clima global atual (BOWMAN et al., 2009). As possíveis condições futuras de atmosfera mais quente e a vegetação mais seca tende a aumentar a ocorrência das queimadas (MIEVILLE et al., 2010; WHITLOCK et al., 2010; MARLON et al., 2013). A alteração do regime de queimadas traz impactos severos na manutenção dos ecossistemas, principalmente, em ambientes onde as queimadas não são naturalmente frequentes (WHITLOCK, 2010).

Dentre os principais impactos das queimadas estão incluídos a alteração da estrutura da vegetação, mortalidade de espécies, perda de biodiversidade e em casos recorrentes de queimada, a degradação permanente da área (ARAÚJO et al., 2013). Os impactos do fogo também são verificados no solo, aqueles com baixa severidade podem trazer benefícios como a renovação da vegetação dominante ao eliminar espécies indesejadas e o aumento de $\mathrm{pH}$ e nutrientes, porém as queimadas de alta intensidade ou com alta recorrência podem causar alterações físicas, físico-químicas, mineralógicas e biológicas do solo, tornando-o menos capaz de absorver água e aumentando a erosão além de eliminar a matéria orgânica e nutrientes (CERTINI, 2005; BENTO-GONÇALVES et al., 2012).

$\mathrm{Na}$ atmosfera, a queima de biomassa causa a emissão de gases e partículas que podem modificar a composição atmosférica e a qualidade do ar (LANGMANN et al., 2009). A emissão de gases, como o Dióxido de Carbono $\left(\mathrm{CO}_{2}\right)$, proveniente de queimadas, desmatamento e mudanças na cobertura da terra altera a capacidade da atmosfera em reter calor, modificando assim o padrão climático do planeta (BOWMAN et al., 2009). A alteração dos níveis de aerossóis também traz impactos ao clima, limitando a formação de nuvens e chuva. Outros elementos emitidos com a queima de biomassa como o monóxido de carbono (CO) e os materiais particulados (MP) causam impactos severos na saúde humana quando respirados em grandes quantidades (RIBEIRO \& ASSUNÇÃO, 2002). 
O monitoramento de áreas queimadas pode auxiliar na melhor fiscalização deste fenômeno pelos órgãos competentes, na estimativa dos seus impactos principalmente aqueles relacionados a emissões de gases e danos a vegetação e na mitigação dos seus efeitos em importantes meios para a vida como a água, vegetação, ar e solos. Com a utilização de séries temporais de sensoriamento remoto, há a possibilidade do monitoramento contínuo deste fenômeno de forma rápida e aprimorando o trabalho de equipes em campo.

O Instituto Brasileiro do Meio Ambiente e dos Recursos Naturais Renováveis (IBAMA) monitora os focos de incêndio ativos em parceria com o Instituto Nacional de Pesquisas Espaciais (INPE) para o Brasil e América do Sul. Diversas imagens de satélite são utilizadas no mapeamento de incêndios, tais como: Advanced Very High Resolution Radiometer (AVHRR); Moderate Resolution Imaging Spectroradiometer (MODIS), Geostationary Operational Environmental Satellite (GOES) e Meteosat Second Generation (MSG) (INPE, 2015b). No entanto, os órgãos federais brasileiros não possuem produtos sistemáticos de áreas queimadas.

No território brasileiro, os dados de focos de incêndio demonstram que os biomas do Cerrado e Amazônia são os mais afetados (Figura 1). A diminuição dos focos de incêndio a partir de 2006 é explicada pela mudança de metodologia utilizada, que reduziu a quantidade de falsos eventos detectados (INPE, 2015b).

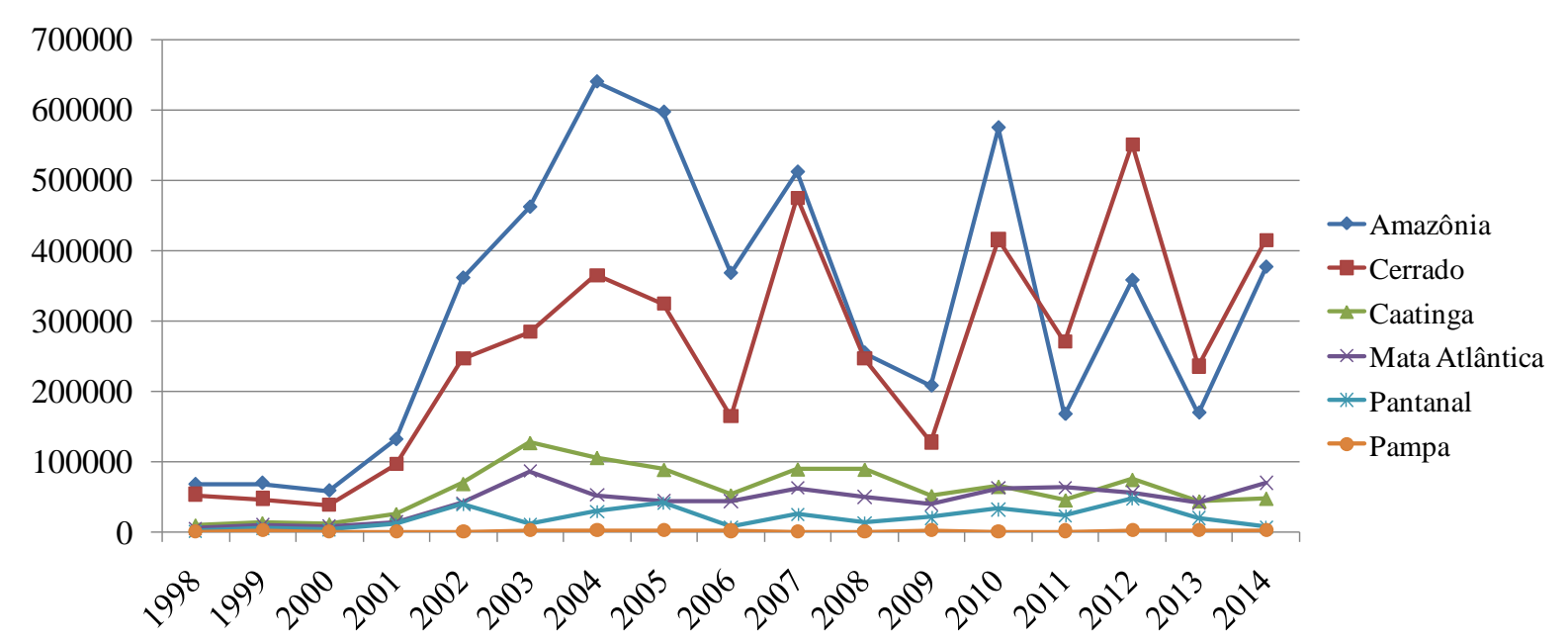

Figura 1: Focos do Incêndio Anuais por Bioma Brasileiro.

Fonte: http://www.inpe.br/queimadas

No bioma do Cerrado o fogo é um elemento constantemente presente, ocorrendo durante a estação seca ou no início da estação úmida, no entanto a influência humana tem sido decisiva para determinar este regime (COUTINHO, 1990). Várias espécies do Cerrado estão 
adaptadas ao fogo, algumas árvores, por exemplo, possuem isolamento térmico e capacidade de armazenamento de água e nutrientes no subsolo (MIRANDA et al., 2009).

As queimadas na Floresta Amazônica têm um impacto diferente daquelas em áreas de Cerrado, pois este bioma não é naturalmente adaptado ao fogo e seus danos na estrutura e florística da vegetação são maiores (COCHRANE \& SCHULZE, 1999; NEPSTAD et al., 1999). Portanto, o bioma da Amazônia se mostra muito vulnerável por não possuir defesas naturais ao fogo e a sua susceptibilidade intensifica com o desmatamento e a degradação florestal nas últimas décadas (CHUVIECO et al., 2014). A ocorrência de queimadas na Amazônia está quase que totalmente ligada a ações humanas, a alta umidade da região impediu que o fogo se tornasse um agente comum em anos úmidos (BUSH et al., 2008). A introdução do fogo ocorre nas regiões onde há intenso desmatamento e mudanças no uso e cobertura do solo (LIMA et al., 2012), e mesmo aquelas áreas onde a floresta ainda não foi derrubada, mas se encontram próximas ao grandes vetores de desmatamento, já são intensamente vulneráveis devido a fragmentação e degradação (COCHRANE \& LAURANCE, 2002).

\subsection{Monitoramento de Queimadas por Imagens Orbitais}

O monitoramento por técnicas de sensoriamento remoto permite a aquisição de informações em áreas extensas ou de difícil acesso (LUNETTA et al., 2006). A possibilidade de utilização de séries contínuas de dados possibilita um maior entendimento das relações na superfície terrestre e tem se mostrado eficaz em detectar, identificar, mapear e monitorar as alterações nos ecossistemas, além de servir como fonte de informações biofísicas básicas como biomassa, temperatura e teor de água na atmosfera (COPPIN et al., 2004; JENSEN, 2009; SAKAMOTO et al, 2005). Estudos globais e regionais, que buscam analisar, por exemplo, as florestas, a geologia, os recursos hídricos e o clima, têm se utilizado destas tecnologias para representar a diversidade dos recursos terrestres e caracterizar a influência do ser humano nos processos naturais (JENSEN, 2009). Desta forma, as séries temporais de imagens orbitais são utilizadas para análises fenológicas (COUTO JUNIOR et al., 2013; SAKAMOTO et al., 2005), monitoramento de desmatamentos (MORTON et al., 2005), monitoramento de queimadas (CARDOZO et al., 2014), entre muitos outros.

A delimitação das áreas queimadas por satélite apresenta vantagens em áreas extensas e de difícil acesso, servindo para mensuração dos efeitos do fogo como a severidade da queimada (LUTZ et al., 2011) ou para a estimativa de liberação de gases de efeito estufa 
(ALENCAR, 2006; SILVESTRINI, 2011), além de servir como apoio para equipes de controle do fogo em campo.

A detecção de fogo a partir de imagens de satélite é realizada de duas formas distintas, a primeira tem o objetivo de detectar os focos de incêndio ativos a partir das alterações térmicas dos alvos, neste caso utilizam-se em geral os canais espectrais do Infravermelho Médio e do Termal (AYANS et al., 2005).

A segunda forma está relacionada ao mapeamento das áreas efetivamente queimadas, com a formação de carvão e cinzas, remoção de vegetação e alteração da sua estrutura, sendo diferenciadas a partir de dados de reflectância e temperatura superficial e técnicas de detecção de mudanças (ROY et al., 2002). A vegetação fotossinteticamente ativa apresenta alta refletância na banda do Infravermelho Próximo (Figura 2), com a ocorrência de uma queimada a resposta se altera e o canal do Infravermelho Próximo passa a refletir menos do que o Infravermelho de Ondas Curtas (PEREIRA et al., 2003).

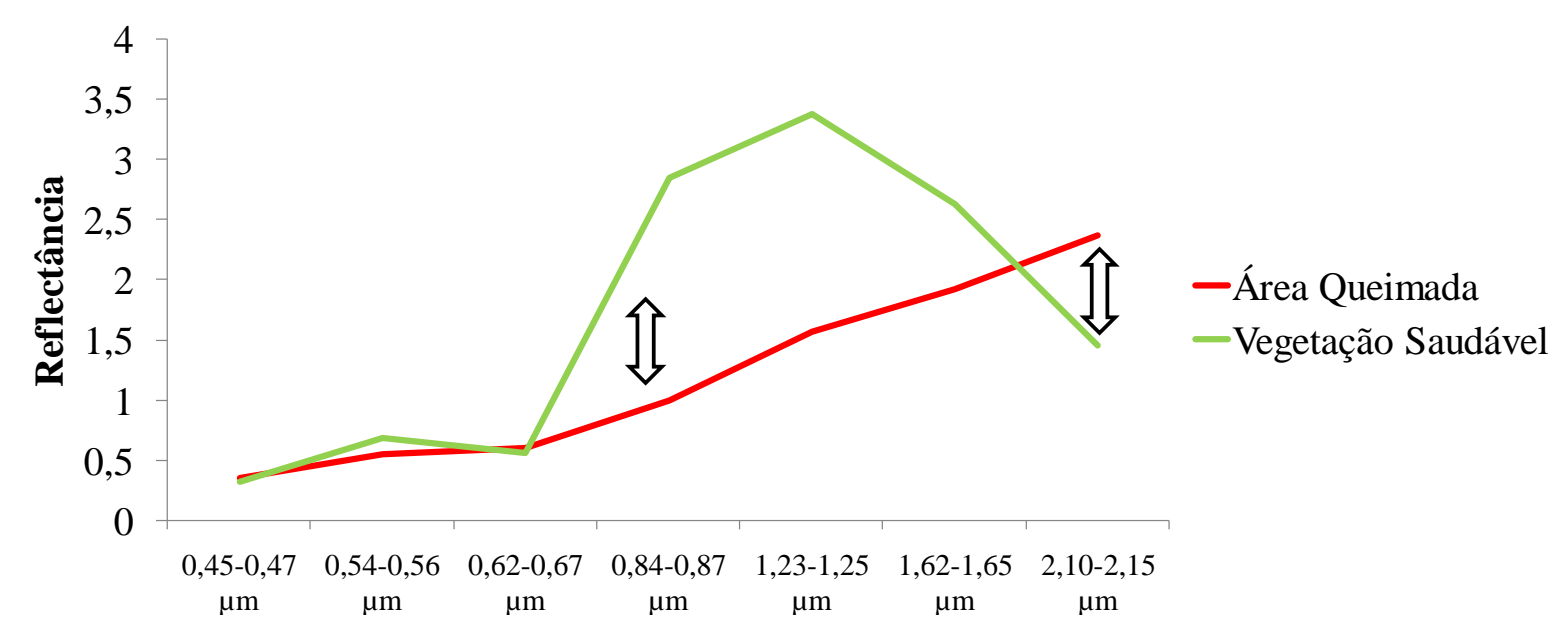

Figura 2: Resposta Espectral de Vegetação Saudável e Vegetação Queimada.

A partir da combinação dos canais espectrais mais sensíveis á ação do fogo, foram desenvolvidos índices que realçam a área queimada e permitem a sua melhor discriminação. Diferentes índices foram utilizados e propostos para análise das áreas queimadas, tais como: Normalized Difference Vegetation Index (NDVI) (DÍAZ-DELGADO et al., 2003), Burned Area Index (BAI) (CHUVIECO et al, 2002), Soil Adjusted Vegetation Index (SAVI) (CHUVIECO et al., 2002), Global Environment Index (GEMI) (Pereira, 1999) e Normalized Burn Ratio (NBR) (KEY \& BENSON, 2006). 
Dentre os índices aplicados, o NBR tem alcançado os melhores resultados em diferentes trabalhos (ESCUIN et al., 2008; LOZANO et al., 2007) e algumas derivações do mesmo como o Normalized Burn Ratio Thermal (NBRT) (HOLDEN et al., 2005) tem apresentado melhor capacidade de diferenciação de áreas queimadas e áreas não queimadas.

Diferentes sensores disponíveis na atualidade são adequados para o mapeamento de áreas queimadas. Os principais sensores utilizados globalmente para este fim são o Moderate Resolution Imaging Spectrometer (MODIS), Vegetation a bordo do satélite SPOT (CHUVIECO et al., 2005), além do sensor Along-Track Scanning Radiometer (ATSR-2) a bordo do satélite European Remote Sensing Sattelite (ERS-2) (MOUILLOT et al., 2014). Na escala de detalhe a série Landsat é a mais utilizada tanto para estimar as áreas queimadas ou para validar o mapeamento de sensores com menor resolução espacial (BASTARRIKA et al., 2011).

Diversos métodos de detecção de queimadas foram desenvolvidos para os sensores disponíveis, porém algumas limitações ainda podem ser identificadas: a resolução espacial dos sensores que causa a omissão de várias áreas queimadas (MOUILLOT et al., 2014), a variação de sinal em função da geometria sol-alvo-sensor (ROY et al., 2002), e a presença de nuvens que é considerada a maior barreira para o mapeamento de focos de incêndio e área queimada (LI et al., 2004).

O monitoramento de queimadas na Floresta Amazônica é importante para a fiscalização e proteção da floresta, porém ainda há certa dificuldade de identificá-las por meio de sensoriamento remoto devido principalmente a quantidade de nuvens na região (SCHROEDER et al., 2005; ARAÚJO et al., 2012). A utilização dos sensores de alta resolução temporal possibilita uma abordagem voltada para a detecção de mudanças a partir de análises temporais. Devido a possibilidade de aquisição de várias imagens ao dia, como no caso do sensor MODIS presente nos satélites Terra e Aqua (JUSTICE et al., 2002b), há a oportunidade do monitoramento da superfície, em regiões com grande cobertura de nuvens, como na Amazônia.

As séries temporais de sensoriamento remoto têm sido utilizadas para a identificação e mapeamento de áreas queimadas e tem apresentado vantagens para o monitoramento deste fenômeno (CARVALHO JÚNIOR et al., 2015; BASTARRIKA et al., 2011; JACQUIN et $a l ., 2011)$. Um dos desafios a se utilizar séries temporais é a presença de ruídos. As imagens podem incluir vários componentes relativos a aerossóis ou fatores de distribuição de reflectância bidirecionais (SAKAMOTO et al., 2005), estes se manifestam no espectro 
temporal na forma de picos abruptos que interferem na análise dos dados ao aplicar valores muito altos ou muito baixos para determinados pixels criando mudanças inverídicas na série (COPPIN et al., 2004). Para reduzir a influência dos ruídos na série temporal tem sido utilizadas técnicas de filtragem ou de composições temporais.

A filtragem tem o objetivo de reduzir os ruídos e construir uma série de alta qualidade que preserve as informações originais, já as composições temporais tem o objetivo de selecionar a partir de uma série restrita de dias, o pixel da série com melhor observação definida pelo usuário, o agrupamento dos melhores pixels dentro da série de dias selecionada originará uma nova imagem (GU et al., 2009). A filtragem da série temporal tem sido realizada a partir de diferentes metodologias, dentre elas os filtros de Savitzky e Golay (1964) e Mediana (ATAMAN et al., 1981) já foram testados com sucesso em biomas brasileiros (ABADE et al., 2015; CARVALHO JÚNIOR et al., 2012).

Além da utilização de técnicas de filtragem, as composições temporais também podem ser utilizadas para reduzir os ruídos da série. Conforme explicitado por Chuvieco et al., (2005) e Barbosa et al., (1998), a utilização de composição temporais poderá remover a maioria dos ruídos com o realce dos objetos de análise, porém algumas desvantagens também são observadas em geral perde-se muita informação já que dentre a série de dias apenas 1 pixel é selecionado reduzindo o total de informações disponíveis, porém o resultado final será uma imagem com grande qualidade.

Um dos métodos de composições temporais que pode ser utilizado são as composições de mínima reflectância no vermelho e infravermelho próximo (DEMPEWOLF et al., 2007). Esta composição é adequada por realçar elementos da superfície como as áreas queimadas, porém as influências de iluminação, ângulo de visada do sensor, condições atmosféricas e sombras de nuvens podem influenciar na acurácia da composição. Em geral tende-se a utilizar dados do canal infravermelho já que as plumas de fumaça são praticamente transparentes para esta região do espectro (MARSHALL et al., 1996).

Outro método utilizado é a composição temporal de focos de incêndio ativos, que servem como requisito para enquadrar uma área como possível queimada (GIGLIO et al., 2006b), ou a composição temporal de máxima temperatura superficial que auxilia no mascaramento de ruídos, já que os pixels com maior temperatura geralmente não serão nuvens (MIETTINEN \& LIEW, 2008).

A combinação de um ou mais métodos tem sido utilizada com a tentativa de se obter o dado com maior confiabilidade. Miettinen \& Liew (2008) ao aplicarem diversos algoritmos 
em uma área tropical úmida, identificaram que a composição mais adequada para o mapeamento de cicatrizes de queimada foi a de mínima reflectância do infravermelho próximo, combinada com métodos de remoção de nuvens e sombras de nuvens. Para Chuvieco et al., (2005) o método mais eficaz de mapeamento na península ibérica foi a combinação de máxima temperatura superficial com o mínimo ângulo de visada do sensor ou mínima reflectância no infravermelho próximo.

Percebe-se, portanto, a diversidade de métodos de mapeamento de área queimada, sendo que, dependendo da área em análise e das suas características ambientais, uma composição poderá ser a mais adequada. Para as áreas de floresta tropical, como na Floresta Amazônica, há uma grande interferência de nuvens que podem dificultar o monitoramento das áreas queimadas, porém a necessidade de monitoramento desta região tem se acentuado pelo alto índice de desmatamento e focos de incêndio nos últimos anos. Neste sentido, observa-se a necessidade de novas metodologias que possam ser aplicadas na região de forma rápida e que resulte em dados úteis e confiáveis. 


\section{MATERIAIS E MÉTODOS}

A Figura 3 demonstra o fluxograma da metodologia aplicada, contendo as seguintes etapas: aquisição de dados, aplicação de índices, filtragem, normalização temporal, mapeamento de áreas queimadas e validação. O presente esquema metodológico foi concebido para permitir fazer diferentes comparações entre métodos nas diferentes etapas de processamento. Desta forma, a pesquisa compara dois tipos de séries temporais (composições de oito dias e dados diários), três índices espectrais e dois tipos de normalização. Além disso, compara os resultados do processamento proposto das imagens MODIS com dados provenientes da interpretação visual de imagens do sensor Landsat (TM/ETM), produto de áreas queimadas do MODIS (MCD45) e os focos de incêndio desenvolvido pelo INPE.

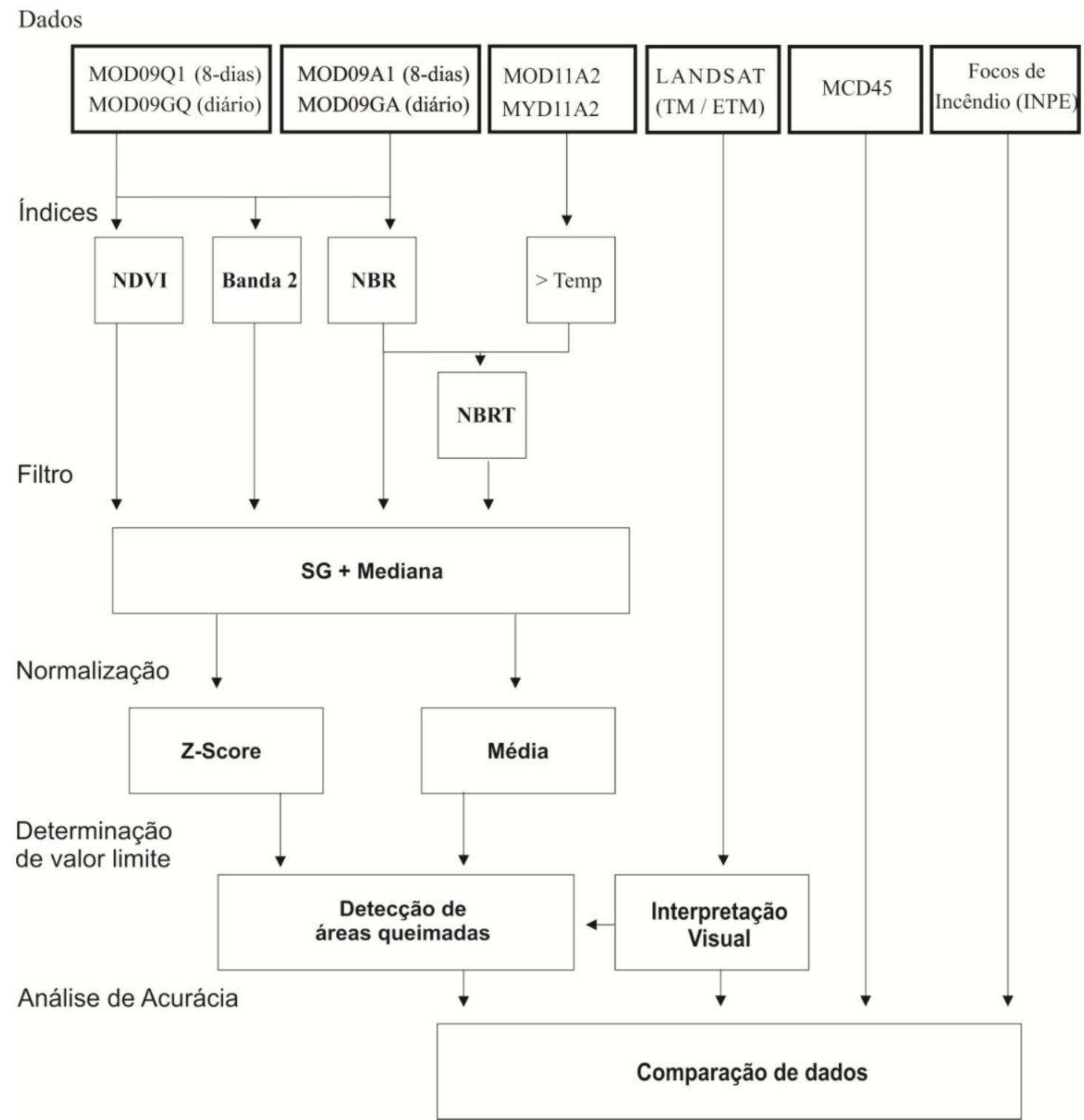

Figura 3: Fluxograma da Metodologia. 


\section{1 Área de Estudo}

A área de estudo é o município de Novo Progresso e entorno, localizada no sudoeste do Estado do Pará, no Sudeste da Amazônia brasileira (Figura 4). A área selecionada é retangular $\left(74552,1562 \mathrm{~km}^{2}\right)$, englobando todo o município de Novo Progresso e parte das áreas de municípios vizinhos. O clima desta região é Equatorial Úmido com precipitação anual variando entre $2050 \mathrm{~mm}$ e $2650 \mathrm{~mm}$ e temperatura média acima dos $25^{\circ} \mathrm{C}$ (IBGE, 2002; INMET, 2015). O período chuvoso ocorre entre os meses de Novembro e Maio e o período seco ocorre entre Junho e Outubro. Os eventos de fogo iniciam no período de estiagem, geralmente no mês de Julho e se estendem até meados de Novembro (INPE, 2015b).

A vegetação local mais abundante é classificada como Floresta Ombrófila Aberta Submontana, contendo também áreas de Savana Florestada e Floresta Estacional Semidecidual Submontana (IBGE, 2008). Diferente das áreas de savanas brasileiras, a vegetação amazônica está pouco adaptada a eventos de queimadas que naturalmente são escassas devido à alta umidade do ar e da floresta (MARTINS et al., 2012). O uso do fogo na região está associado basicamente ao desmatamento e manutenção das pastagens nas propriedades, a prática constante de queimadas associadas à fragmentação florestal, tem tornado a região, a cada ano, mais susceptível a eventos de queimadas (COCHRANE, 2001; ALENCAR et al., 2015).

Secularmente, esta região tem sido habitada por populações indígenas, que atualmente estão restritas dentro das Reservas Indígenas: Terras Indígenas Baú e Menkragnoti. Essas reservas preservam a cultura das populações indígenas e auxiliam na preservação dos recursos naturais (ZIMMERMAN et al., 2001). A ocupação recente dessa área é proveniente da construção da rodovia federal BR-163 na década de 1980, que objetivou conectar e povoar a Amazônia Brasileira (FEARNSIDE, 2007). A construção da rodovia trouxe um intenso fluxo migratório que tem aumentado com a expansão da pecuária e cultura da soja na região e projetos de infraestrutura como pavimentação e hidrelétricas (FEARNSIDE, 2007).

Na região existem Unidades de Conservação que coíbem o aumento do desmatamento e preserva a biodiversidade, sendo diferenciadas entre Unidades de Proteção Integral (Parque Nacional do Rio Novo, Parque Estadual Cristalino, Reserva Biológica Nascentes da Serra do Cachimbo e Reserva Particular do Patrimônio Natural Cristalino) e Unidades de Uso Sustentável (Florestas Nacionais do Jamanxim e de Altamira, Floresta Estadual do Iriri e Área de Proteção Ambiental do Tapajós). Outros usos como Assentamentos da Reforma Agrária e Terras Militares compõe o quadro fundiário da região. 

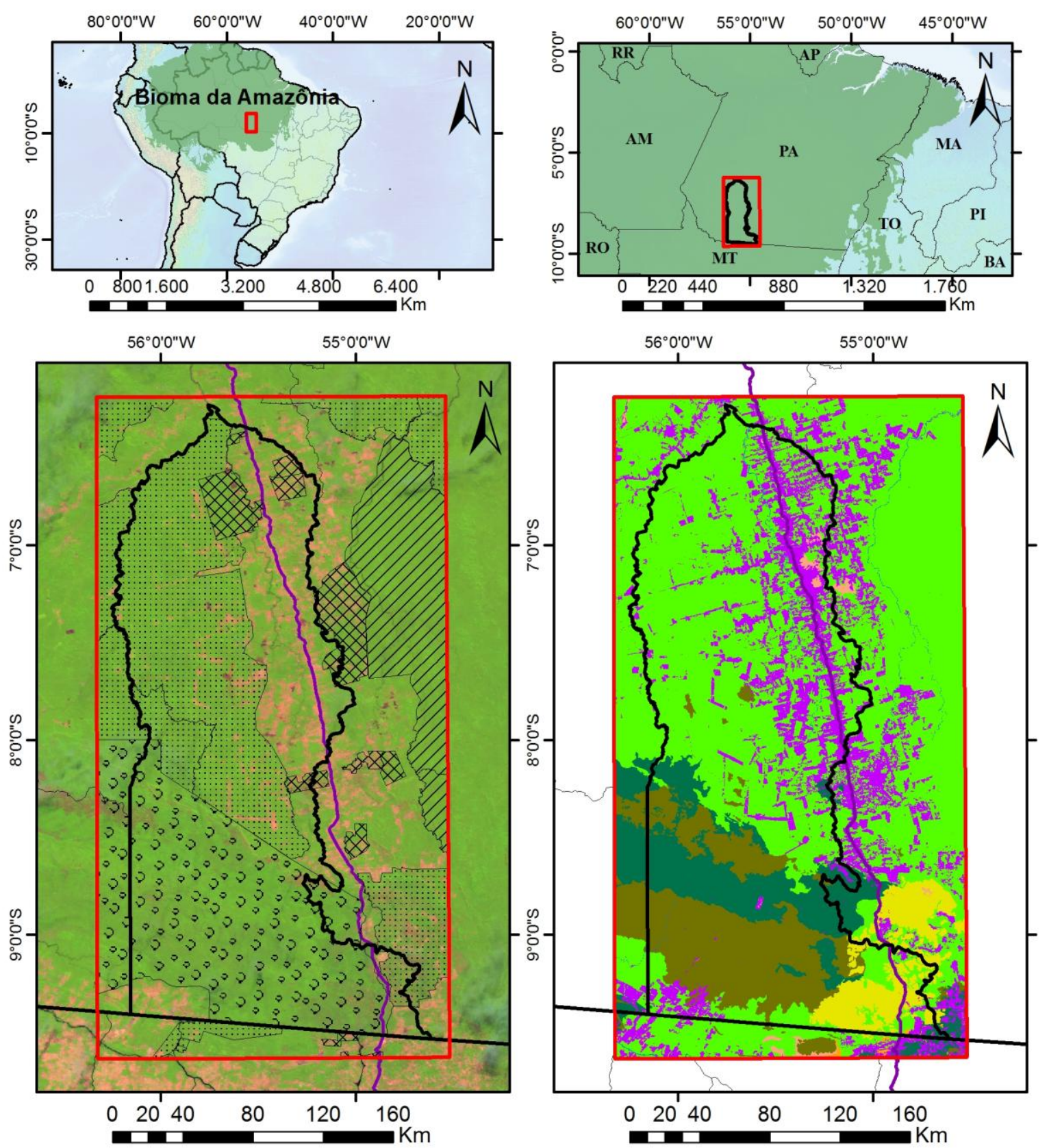

\section{Legenda}

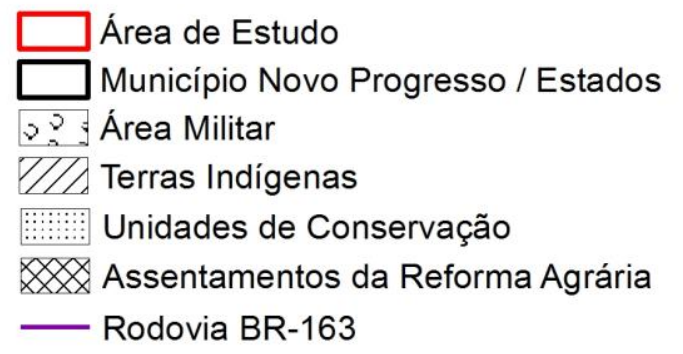

Agricultura

Vegetação Secundária

Campinarana

Desmatamento Acumulado

2014

Floresta Estacional

Floresta Ombrofíla

Savana

Massa d'água

Figura 4: Área de Estudo, Categorias e Tipo de Cobertura da Terra. 


\subsection{Imagens MODIS}

O sensor MODIS está presente nos satélites Terra lançado em 1999 e Aqua lançado em 2002, compondo o Programa EOS (Earth Observing System) liderado pela Nasa (National Aeronautics and Space Administration), sendo projetado para fornecer observações da superfície terrestre, nas regiões do visível e infravermelho, a cada dois dias (SOARES et al., 2007). Este sensor dispõe de 36 bandas espectrais entre o intervalo de $0,4 \mu \mathrm{m}$ a $14,4 \mu \mathrm{m}$ do espectro eletromagnético, sendo que duas destas bandas possuem resolução espacial de 250 metros, cinco de 500 metros e as restantes de 1 quilômetro. Sua varredura contempla uma faixa de 2330 quilômetros a cada 2 dias. Diversos produtos derivados foram desenvolvidos das 36 bandas espectrais do sensor MODIS, dentre eles há produtos de reflectância de superfície, temperatura superficial, cobertura de gelo, índices de vegetação, anomalias termais, dentre outros (JUSTICE et al., 2002b).

Dos produtos disponíveis a partir das imagens MODIS, os produtos de reflectância (bandas 1 a 7) podem ser adquiridos em dados diários ou composições temporais de 8 ou 16 dias para melhorar a qualidade da imagem. Cada pixel da composição temporal contém a melhor observação possível dentro de 8 ou 16 dias com base na cobertura da observação, baixo ângulo de visada, ausência de nuvens ou sombras de nuvens e carga de aerossóis (CHEN et al., 2013). A utilização de composições temporais deverá ser observada com cautela, porque pode haver perda de informações úteis do fenômeno observado, enquanto que as imagens diárias apresentam uma maior influência de ruídos e efeitos atmosféricos que também podem acarretar na perda de informações.

O sensor MODIS tem se tornado um dos mais utilizados na detecção de áreas queimadas devido a sua alta resolução temporal de 2 dias e a capacidade de obtenção de dados em áreas extensas e em diversas regiões do espectro eletromagnético (MOUILLOT et al., 2014). Neste estudo foram utilizados os produtos MODIS: (a) reflectância de superfície MODIS/Terra 250 e 500m relativos às composições de 8 dias (MOD09A1 e MOD09Q1) e diárias (MOD09GQ e MOD09GA); (b) Temperatura Superficial Diária dos satélites MODIS/Terra e Aqua 1km (MOD11A2 e MYD11A2); e (c) mapeamento de cicatrizes de queimadas (MCD45A1) (ROY et al., 2008). As imagens MODIS foram adquiridas para o período 2000-2014, sendo selecionadas as imagens do período de seca (Julho a Novembro) com maior incidência de queimadas. Apenas imagens com baixa cobertura de nuvens foram selecionadas para evitar erros de classificação relacionados às sombras, aquelas com cobertura de nuvens que ocupassem mais de $50 \%$ da área de estudo foram descartadas, 
resultando em um total de 234 imagens de composições de 8 dias selecionadas dentro do conjunto de 345 imagens, e 435 imagens diárias selecionadas dentro do conjunto de 2183 imagens. As imagens foram projetadas para projeção UTM e amostradas para 250 metros para compatibilidade dos dados.

\section{3 Índices Espectrais}

$\mathrm{Na}$ detecção das áreas queimadas, os seguintes dados foram comparados: (a) somente a banda do infravermelho próximo do produto MOD09 (banda 2), (b) o índice NBR, (c) o índice NDVI e (d) e o índice NBRT. A banda do Infravermelho Próximo (Banda 2) permite uma alta separabilidade das áreas queimadas, se comparada com outros canais espectrais (PEREIRA et al., 1999; MAIER, 2010). A Tabela 1 lista a formulação dos índices espectrais testados nessa pesquisa. O índice NBR, desenvolvido para ressaltar as áreas queimadas considera as bandas do Infravermelho Próximo (NIR) e do Infravermelho de Ondas Curtas (SWIR) (Key \& Benson, 2006). O índice de vegetação NDVI é calculado a partir da diferença normalizada entre as bandas do Vermelho (RED) e NIR. O índice NBRT utiliza as bandas do NIR e SWIR (MOD09) e a composição de Máxima Temperatura Superficial (MOD14) (HOLDEN et al., 2005; HARRIS et al., 2011), elaborada pela composição do maior valor de temperatura diária entre as imagens dos satélites AQUA e TERRA (CHUVIECO et al., 2005).

Tabela 1: Índices Espectrais Utilizados.

\begin{tabular}{|c|c|c|}
\hline Índice & Fórmula & Estudo \\
\hline NBR & $N B R=\frac{N I R-S W I R}{N I R+S W I R}$ & Key \& Benson, 2006 \\
\hline NBRT & $N B R T=\frac{N I R-S W I R * T e m p e r a t u r \alpha}{N I R+S W I R * T e m p e r a t u r \alpha}$ & Holden et al., 2005 \\
\hline NDVI & $N D V I=\frac{N I R-R E D}{N I R+R E D}$ & Rouse et al., 1974 \\
\hline
\end{tabular}




\subsection{Eliminação de Ruídos na Série Temporal}

Os ruídos presentes nas séries temporais provenientes do sensor, erros de transmissão, efeitos atmosféricos e termais podem ocasionar falsas mudanças na superfície terrestre (CORNER et al., 2003). No mapeamento de áreas queimadas, a principal causa de falsa detecção é a sombra de nuvens, devido a sua resposta semelhante à área queimada na faixa do infravermelho próximo (ZHANG et al., 2015). Um procedimento para minimizar essas inferências é a aplicação de filtros temporais para eliminação de ruídos e suavização da série temporal.

Conforme Hird e McDermid (2009), os filtros são altamente influenciados pela região geográfica e variações anuais da vegetação, portanto estes fatores devem ser observados e em casos específicos há a necessidade de aplicação de mais de um método de filtragem para verificar a adequação de cada um na região em estudo. No presente trabalho foi utilizada uma combinação de duas técnicas de filtragem: mediana (NARENDRA, 1981) e Savitzky-Golay (S-G) (SAVITZKY \& GOLAY, 1964). Os dois procedimentos de filtragem foram realizados utilizando o programa ABÍLIO (CARVALHO JÚNIOR et al., 2008).

A utilização do filtro de Mediana se mostra necessária em áreas como a Amazônia, onde ocorrem ruídos do tipo impulso devido à intensa presença de nuvens. A mediana é uma técnica de suavização não linear que permite preservar mudanças bruscas na série temporal, ao mesmo tempo em que remove ruídos de impulso que não poderiam ser eliminados utilizando-se de algoritmos lineares (ATAMAN et al., 1981). O filtro utiliza uma janela móvel ao longo da série temporal, onde o valor do pixel central é substituído pela mediana dos pixels de sua vizinhança temporal. Este filtro mostra-se adequado para eliminar os ruídos do tipo impulso, que são valores anômalos oriundos de erros de sinal. A largura da janela é determinada pelo usuário e deverá ser maior em regiões com maior presença de nuvens e sombras de nuvens, em geral janelas com largura $=3$ são suficientes para eliminar estes elementos (CARVALHO JÚNIOR et al., 2012). Para que não houvesse interferência com as áreas queimadas, limitando-se ao ruído, foi utilizada uma janela de dimensão igual 3.

O filtro S-G foi desenvolvido para séries de espectros químicos e utiliza polinômios de mínimos quadrados em intervalos da série removendo ruídos e preservando a forma do espectro (SCHAFER, 2011). Assim, o método S-G utiliza uma janela móvel com valores ponderados, cujos pesos são provenientes de um polinômio de grau definido pelo usuário. Chen et al. (2004) adequou o método para o método S-G para o tratamento de séries temporais MODIS, sendo amplamente utilizado (ABADE et al., 2015). Este filtro apresenta 
vantagens no tratamento de séries temporais para a detecção de áreas queimadas, pois permite preservar os valores mínimos relativos às feições de fogo (CARVALHO JÚNIOR et al., 2015; KINOSHITA \& HOGUE, 2011; VERAVERBEKE et al., 2010, VERBESSELT, 2006). No presente trabalho, a dimensão da janela utiliza foi de 5. A Figura 5 demonstra a aplicação dos dois filtros em uma série temporal, evidenciando a eliminação dos ruídos de impulso pelo filtro de mediana e a suavização da curva pelo método $\mathrm{S}-\mathrm{G}$.
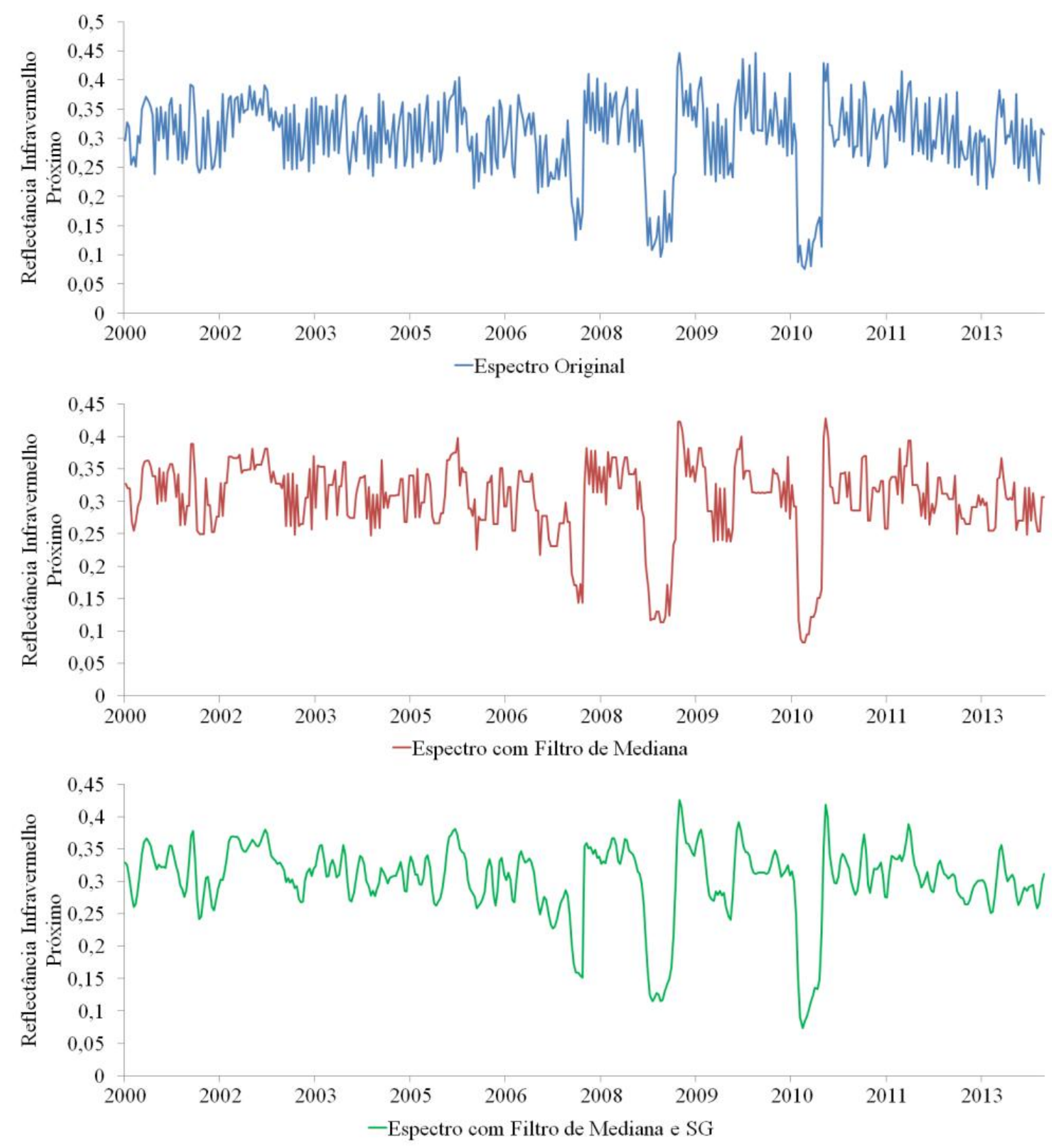

Figura 5: Exemplo de Filtragem da Série Temporal de Reflectância MODIS (Banda 2) em área de pastagem. 


\subsection{Normalização Temporal}

As áreas queimadas apresentam comportamento espectral um pouco diferente conforme o tipo de cobertura da terra, o que impede que seja utilizado um valor espectral fixo para a detecção entre áreas queimadas e não queimadas nos diferentes ambientes. No caso da Floresta Amazônica, as queimadas ocorrem principalmente em áreas de pastagem e agricultura, porém há impactos significativos em áreas florestais e campestres (CARDOZO et $a l .$, 2014; SHIMABUKURO et al., 2009), que se caracteriza por valores distintos. Como exemplificação, a Figura 6a apresenta séries temporais filtradas do infravermelho próximo (Banda 2) referentes aos alvos: água, pastagem e savana.
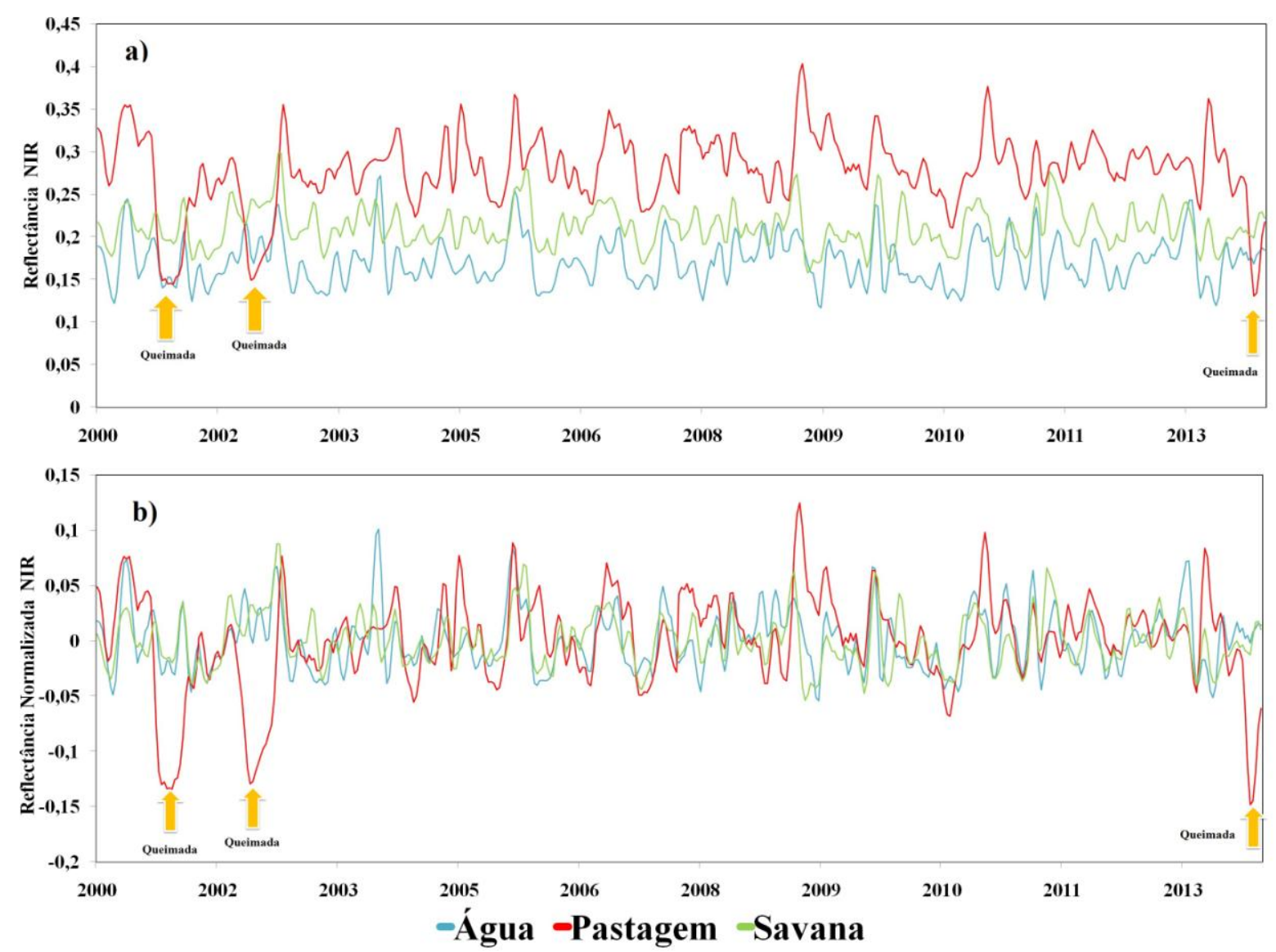

Figura 6: Separação de alvos queimados e não queimados. (a) Espectros refletidos no Infravermelho Próximo sem Normalização. (b) Espectros refletidos no Infravermelho Próximo com Normalização por média.

As feições de áreas queimadas em savana apresentam valores próximos aos corpos d'água e as vegetações rasteiras que não foram queimadas, evidenciando a sobreposição de valores e a incapacidade de distinção por um único valor limite entre as séries temporais. Com a aplicação de normalização dos espectros é possível separar as áreas queimadas em savana 
dos outros alvos com resposta semelhante (Figura 6b). Foram utilizados dois métodos de normalização para identificar o mais adequado para a separação de áreas queimadas, o método Z-score e o método por média. $\mathrm{O}$ método Z-score torna a média igual a 0 e o desvio padrão igual a 1 , enquanto que o método de normalização por média considera apenas a média igual a zero. O método z-score foi adotado com sucesso para regiões de vegetação savana (CARVALHO JÚNIOR et al., 2015).

Conforme demonstrado na Figura 7, as áreas de savana e cursos d'água apresentam tons de cinza semelhante ás áreas queimadas, portanto são confundidas quando aplicado um valor limite.

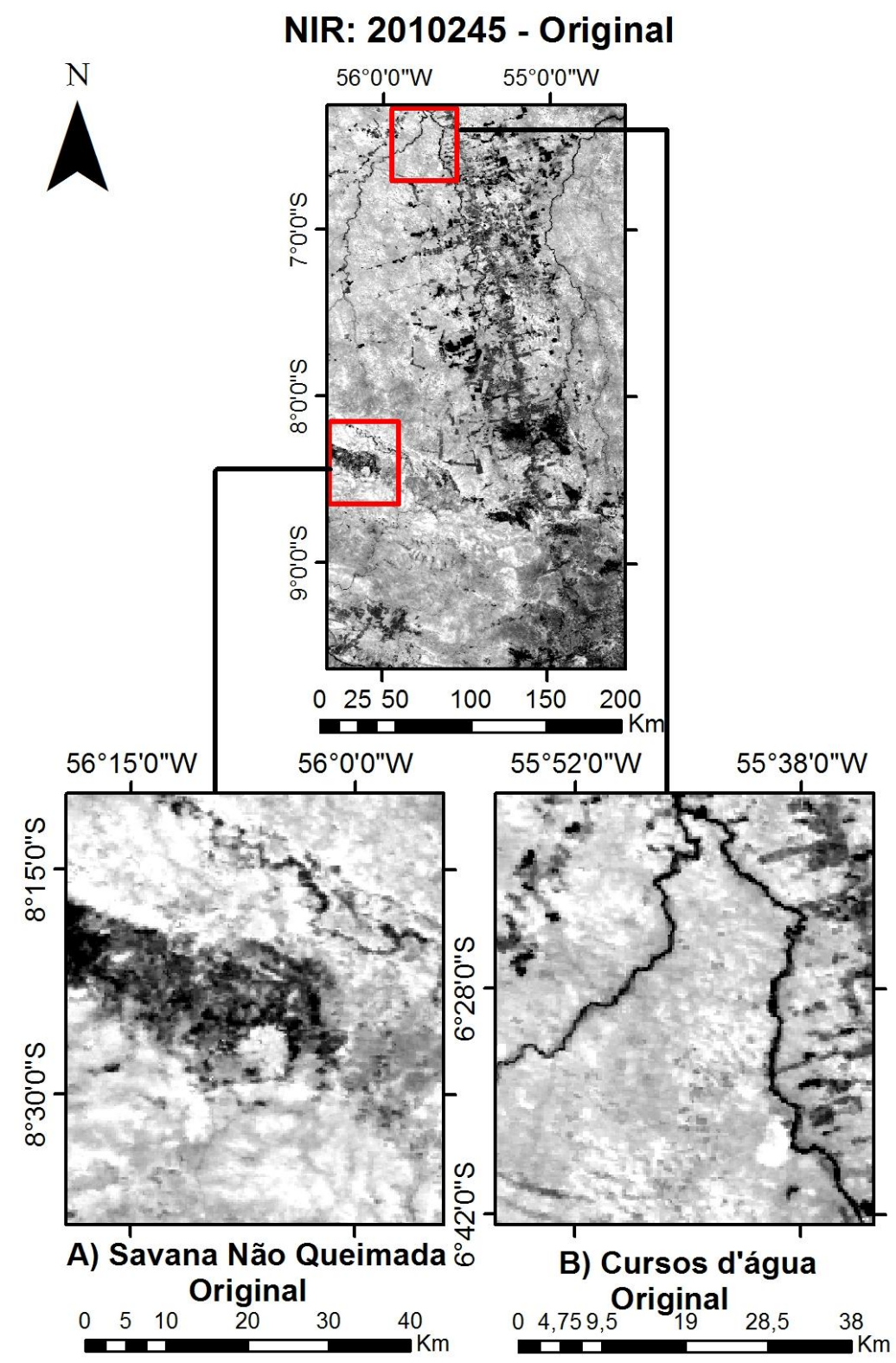

Figura 7: Exemplo de Alvos não Queimados no Canal do Infravermelho Próximo. 
Na Figura 8 observa-se a aplicação da normalização pela média, onde as áreas antes detectadas como queimadas relativas aos corpos d'água, vegetação rasteira e solo exposto deixam de apresentar valores próximos da queimada permitindo a sua separação.

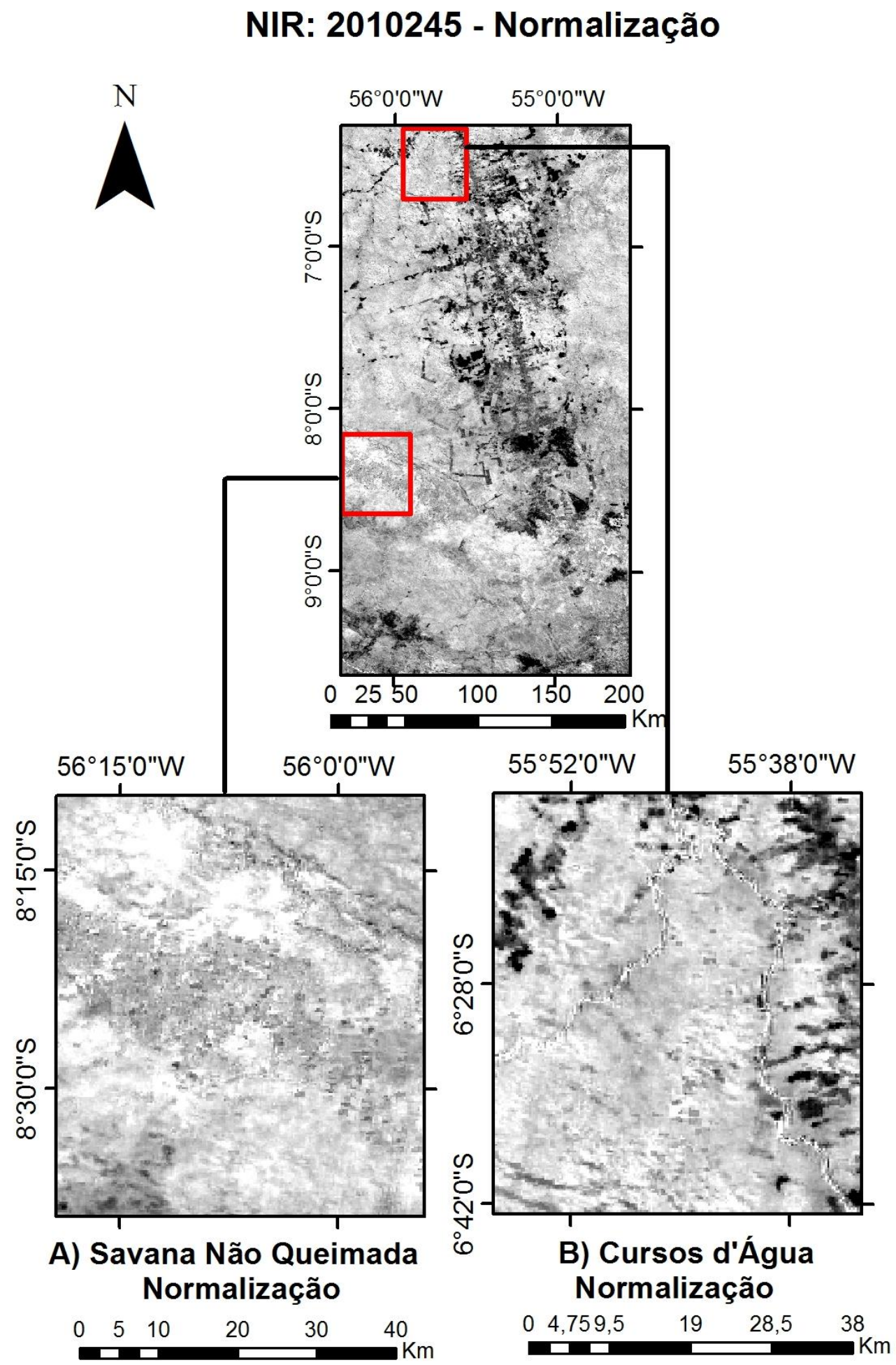

Figura 8: Exemplo de Alvos não Queimados no Canal do Infravermelho Próximo após Normalização. 


\subsection{Mapeamento de Áreas Queimadas}

A identificação do melhor valor limite a ser utilizado na separação entre áreas queimadas e não queimadas foi baseada na metodologia aplicada por Carvalho Júnior et al. (2015). Este procedimento compara um mapa de referência das áreas queimadas, previamente obtido a partir da classificação de uma imagem de melhor resolução espacial, e as classificações utilizando diferentes valores limites de uma banda ou índice espectral do sensor MODIS. O valor limite que apresenta o melhor ajuste pelo coeficiente Kappa (CONGALTON \& GREEN, 1999) com a imagem de referência é adotado para as demais imagens da série temporal. A Figura 9 exemplifica a curva de valores Kappa entre uma classificação de referencia, proveniente da imagem Landsat ETM do dia 15/08/2001, e os resultados das classificações utilizando diferentes valores limites da banda 2 normalizados pela média do sensor MODIS do mesmo dia. Neste caso, o valor limite de $-947,098$ obteve o melhor Kappa $(74,07)$.

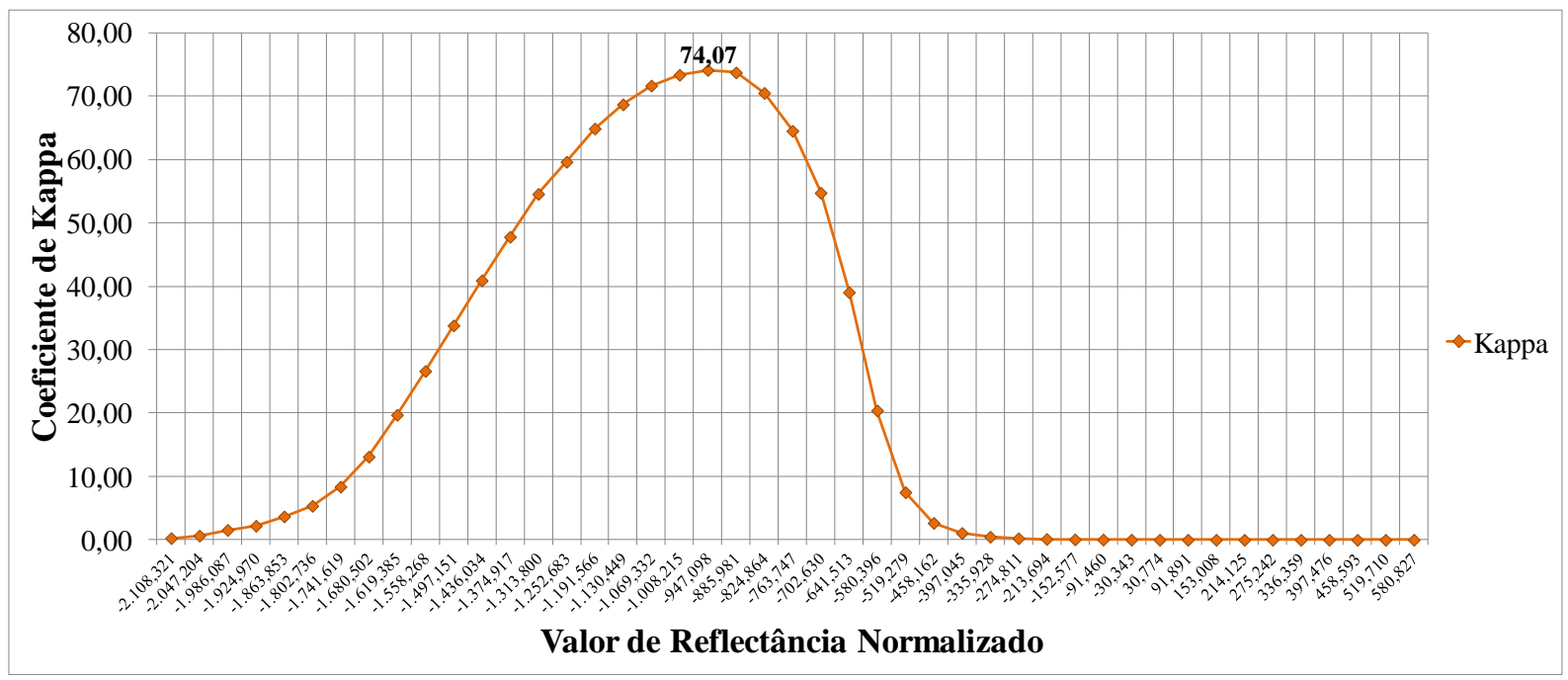

Figura 9: Definição do valor limite para 2001. A partir do calculo do Coeficiente de Kappa para cada valor de pixel no Infravermelho Próximo é definido o valor com o melhor resultado.

No presente trabalho, a definição do valor limite utilizou cinco mapas de referência de áreas queimadas produzidos por interpretação visual de imagens dos sensores Landsat TM e ETM (órbita/ponto 227 - 65) nas seguintes datas: 15/08/2001, 19/09/2002, 30/07/2004, 03/09/2005 e 01/09/2010. Os testes foram realizados em uma área reduzida, correspondendo a $19 \%$ da área de estudo $\left(14497,119 \mathrm{~km}^{2}\right)$ com alta ocorrência de queimadas. A média dos cinco melhores valores limites foi aplicada na série temporal completa de 14 anos, gerando 
uma série temporal de máscara de áreas queimadas. As áreas queimadas anuais foram obtidas pela união de todos os polígonos sobrepostos de um mesmo ano. As áreas de queimada que não ocorreram em pelo menos duas datas consecutivas foram eliminadas por serem considerados ruídos, uma vez que o período da rebrota de savana e floresta requer um tempo mais longo (EVA \& LAMBIN, 2000; PEREIRA et al., 1999; PARRINI \& OWEN-SMITH, 2010).

\subsection{Análise de Acurácia e Comparação dos dados}

A análise de acurácia foi realizada entre a máscara de queimadas geradas a partir das imagens MODIS e a interpretação visual em duas imagens (28 de Julho de 2003 e 10 de Agosto 2008) dos sensores ETM e TM na área equivalente a 19\% da área de estudo total $\left(14497,119 \mathrm{Km}^{2}\right)$. A análise considerou a composição temporal de 8 dias e a diária.

Os resultados obtidos foram comparados com o produto MCD45 e o mapeamento utilizando imagens Landsat. O produto de mapeamento global de queimadas MCD45 (ROY et al., 2008), se utiliza de um modelo baseado na detecção de mudanças rápidas na reflectância superficial diária. O algoritmo estima a reflectância para dias futuros em diversas bandas espectrais, com a alteração deste padrão e a eliminação de falsos eventos como sombras de nuvens, pode-se identificar os pixels queimados diariamente. Este produto é disponibilizado em arquivos mensais com 500 metros de resolução, onde cada pixel poderá indicar o dia exato da queimada em dias julianos (1-365), área não queimada, área de nuvens ou de água (ROY et al., 2005).

Os focos de incêndio detectados por satélite e processados no Brasil pelo INPE também foram utilizados para validar o mapeamento de áreas queimadas. Foram selecionados os focos de incêndio correspondentes aos satélites AQUA e TERRA, ATSR, GOES, METEOSAT, NOAA, NPP e TRMM (INPE, 2015b).

\subsection{Análise dos eventos de fogo pela classe de uso e ocupação da terra}

No presente estudo foram analisados os eventos de fogo considerando toda a área de estudo e os diferentes usos e ocupações da terra a partir dos dados de mapeamento produzidos pelo Sistema de Vigilância da Amazônia (SIVAM) (IBGE, 2008) e de desmatamento produzidos pelo Instituto Nacional de Pesquisas Espaciais (INPE, 2015a). As classes de uso e 
cobertura da terra no mapeamento do SIVAM foram definidas como (IBGE, 2008): Florestas Ombrófilas, Florestas Estacionais, Floresta Sazonal, Campinarana, Savana, Refúgios Vegetacionais, Vegetação Secundária, Agricultura, Desmatamento Anual e Água. O monitoramento de desmatamento realizado pelo INPE considera um período de um ano iniciando em Agosto. Nós utilizamos imagens dos satélites Landsat para atualizar o desmatamento até o final de cada ano de 2000 a 2014.

A comparação das áreas queimadas com o tipo de proprietário da terra foi realizada a partir de um conjunto de bases de dados disponibilizadas pelas instituições brasileiras responsáveis: Unidades de Conservação (ICMBIO, 2015), Terras Indígenas (FUNAI, 2015), Área Militar Aproximada (IMAZON, 2015), Assentamentos de Colonização da Reforma Agrária (INCRA, 2015). 


\section{RESULTADOS}

\subsection{Determinação do Melhor Valor Limite para Detecção de Áreas Queimadas}

A Tabela 2 lista os resultados de cada teste realizado para a definição do melhor valor limite. As imagens diárias apresentaram maior exatidão geral, sendo mais indicadas para o mapeamento de áreas queimadas do que as composições de 8 dias. A normalização pela média obteve melhores resultados do que por Z-score, que por incluir áreas não queimadas reduz a sua qualidade. A utilização de índices não apresentou melhora na capacidade de mapeamento de áreas queimadas nesta região, sendo a banda do Infravermelho Próximo a com maior Kappa e acurácia geral.

Tabela 2: Definição de Valor Limite para os diferentes métodos testados.

\begin{tabular}{|c|c|c|c|c|c|c|c|}
\hline & \multicolumn{7}{|c|}{ Normalização: Z-score } \\
\hline & \multicolumn{3}{|c|}{ Composição 8 dias } & \multicolumn{4}{|c|}{ Diário } \\
\hline & NDVI & NBR & Banda 2 & NDVI & NBR & NBRT & Banda 2 \\
\hline $\begin{array}{l}\text { Valor } \\
\text { Limite }\end{array}$ & $-1,238$ & $-1,777$ & $-1,852$ & $-1,314$ & $-1,109$ & $-2,103$ & $-2,111$ \\
\hline Kappa & 22,92 & 27,89 & 67,37 & 25,9 & 47,32 & 26,7 & 71,04 \\
\hline \multirow[t]{4}{*}{ Overall } & 97,068 & 97,069 & 98,297 & 97,231 & 97,98 & 97,282 & 98,37 \\
\hline & \multicolumn{7}{|c|}{ Normalização: Média } \\
\hline & \multicolumn{3}{|c|}{ Composição 8 dias } & \multicolumn{4}{|c|}{ Diário } \\
\hline & NDVI & NBR & Banda 2 & NDVI & NBR & NBRT & Banda 2 \\
\hline $\begin{array}{l}\text { Valor } \\
\text { Limite }\end{array}$ & $-0,154$ & $-0,239$ & $-726,626$ & $-0,2732$ & $-0,270$ & $-0,25$ & $-814,048$ \\
\hline Kappa & 48,48 & 59,96 & 71,62 & 50,78 & 62,32 & 56,58 & 73,73 \\
\hline Overall & 97,629 & 98,044 & 98,375 & 97,838 & 98,13 & 97,859 & 98,627 \\
\hline
\end{tabular}

Mesmo sendo indicado para o mapeamento de áreas queimadas, o índice NBR apresentou baixo coeficiente Kappa. Isto se deve à dificuldade da separação entre as extensas áreas de solo exposto e as áreas queimadas, em alguns casos o solo exposto apresenta menor valor de NBR do que a área queimada (Figura 10). Os índices NBRT e NDVI apresentaram 
menores valores de Acurácia Geral e Coeficiente Kappa do que a banda 2 do sensor MODIS e o índice NBR.

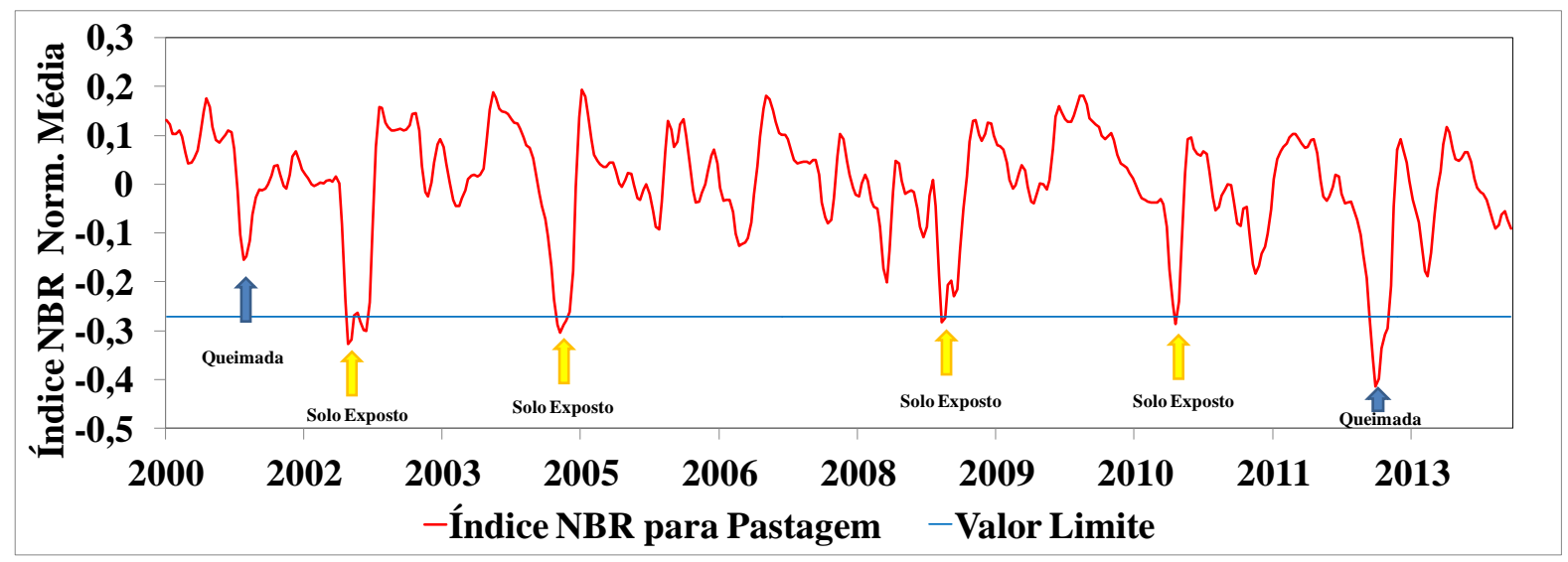

Figura 10: Identificação de Queimadas com o índice NBR.

\subsection{Caracterização Temporal das Ocorrências de Queimadas}

A caracterização temporal das ocorrências de queimadas na região adotou as imagens diárias da banda 2 com normalização por média, que obteve o maior valor de Acurácia Geral e coeficiente Kappa. A área anual queimada variou entre $484 \mathrm{~km}^{2}(<1 \%$ de área queimada) e $2583,7 \mathrm{~km}^{2}$ (> 3\% da área queimada) (Figura 11).

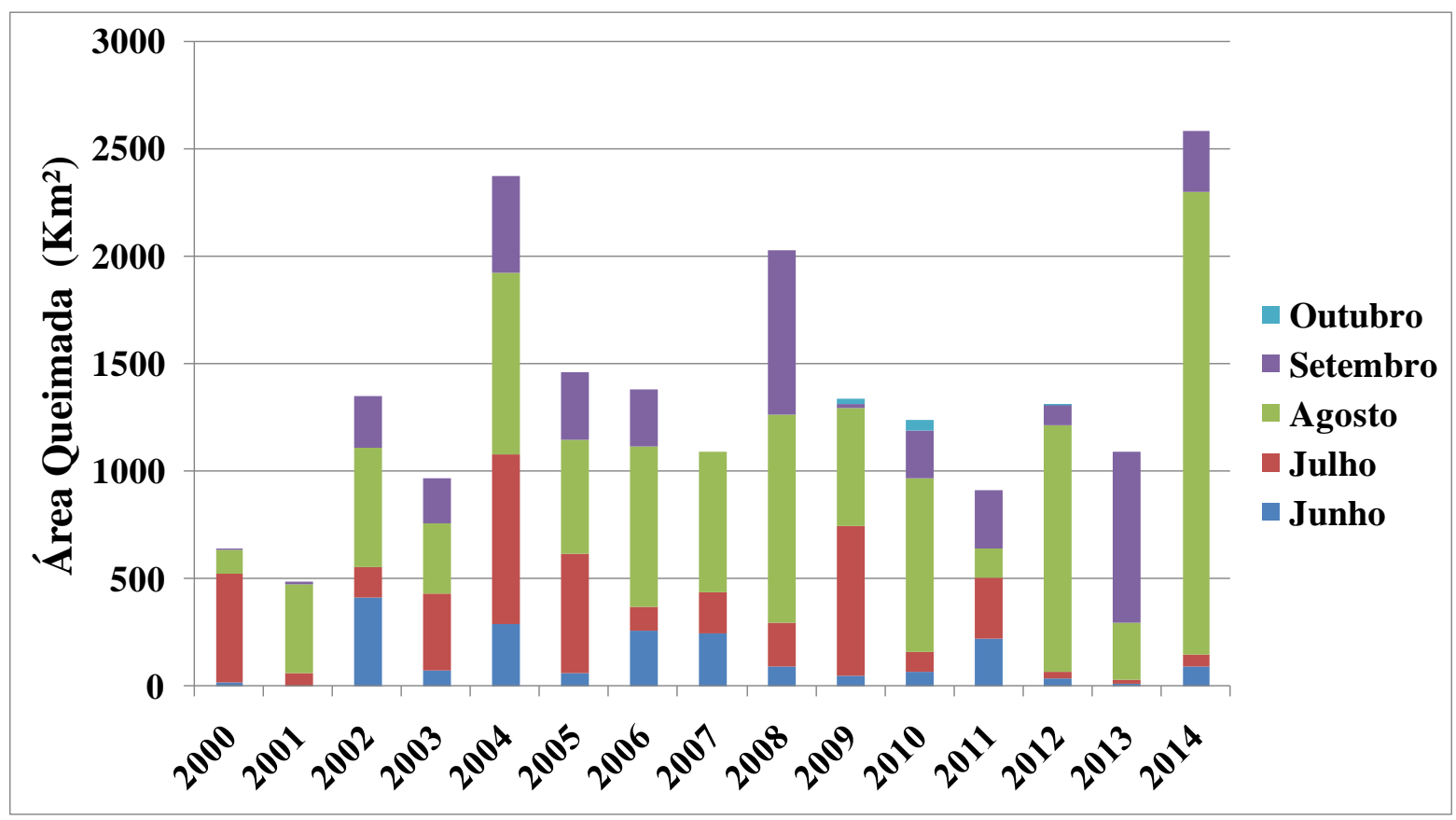

Figura 11: Área Queimada Anualmente (Junho a Novembro), Imagens MODIS Diárias. 
A região apresentou uma tendência de aumento de área queimada ao longo dos anos, sendo que o ano de 2014 foi o de maior proporção, os outros grandes picos foram em 2004 $\left(2400 \mathrm{~km}^{2}\right)$ e $2008\left(2000 \mathrm{~km}^{2}\right)$. No recorte anual analisado, entre os meses de Junho a Dezembro, os meses de Agosto e Setembro apresentaram as maiores quantidades de área queimada, enquanto nos meses de Novembro a Dezembro, início do período chuvoso, não foram detectados pixels queimados. A intensa presença de nuvens nesta época do ano inviabiliza a detecção de áreas queimadas no período úmido.

A Figura 12 representa a localização das queimadas mapeadas para cada ano a partir das imagens diárias. É possível perceber que os maiores fragmentos estão localizados nas proximidades da rodovia BR-163, diminuindo com o distanciamento da rodovia e adentrando em áreas com grande parte da floresta não desmatada. O método se mostrou eficaz em separar as áreas de queimadas em vegetação rasteira como savanas e pastagens, sendo na região Amazônica as principais áreas de queimadas. Também obtivemos bons resultados em áreas queimadas em Florestas, porém em certos casos a densa cobertura do dossel dificulta a separação de queimadas com predominância no sub-bosque.

\subsection{Vegetação Afetada pelo Fogo}

Com o cruzamento dos pixels com queimadas anuais e o tipo de cobertura do solo (Tabela 3), constatou-se a grande relação entre área total queimada e o desmatamento $\left(\mathrm{r}^{2}=0,95\right)$. O desmatamento é o tipo de cobertura do solo com maior representatividade nos anos estudados, sendo responsável por mais de $70 \%$ da área total queimada anualmente. Isso atesta a influência antrópica nos padrões de queimadas atuais, seja utilizando-se do fogo para o desmatamento em novas áreas ou para a manutenção de pastagens e agricultura.

As áreas de Floresta Ombrófila, que cobriam 70\% da área de estudo em 2000 e 59\% em 2014, foram responsáveis por grande parte dos registros de queimadas, nos anos de 2000, 2008, 2009, 2011, 2013 e 2014, onde foram detectadas mais queimadas em áreas de Floresta Ombrófila do que em áreas recém-desmatadas. Em relação à proporção de área queimada e área total dentro da área de estudo, a classe de desmatamento foi a que apresentou maior proporção de queimadas. No ano de 2004 mais de $24 \%$ de áreas desmatadas foram queimadas, já em 2009 foram menos de 6\%. Os outros tipos de vegetação como Savanas, Florestas Estacionais e Vegetação Secundária apresentaram baixa proporção de área queimada em todos os anos, em média menos de $1 \%$ destas áreas foram afetadas. 

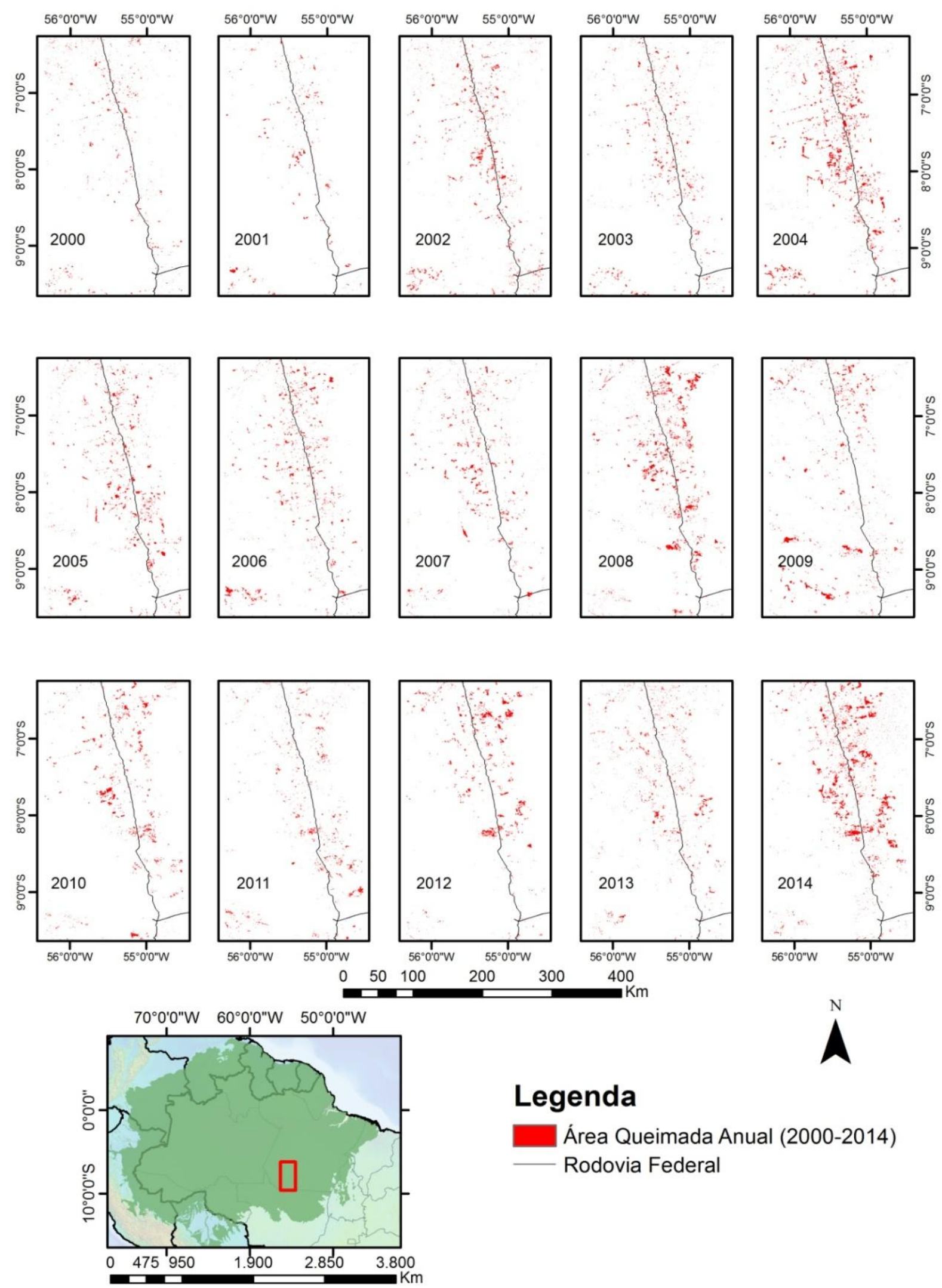

\section{Legenda}

Área Queimada Anual (2000-2014)

Rodovia Federal

Figura 12: Área Queimada Anualmente: 2000 - 2014. 
Tabela 3: Ocorrência de queimadas anuais por uso e cobertura da terra a partir de imagens MODIS diárias.

\begin{tabular}{|c|c|c|c|c|c|c|c|c|}
\hline \multicolumn{9}{|c|}{ Ano/ Área Queimada $\left(\mathrm{Km}^{2}\right)$} \\
\hline Ano & $\mathrm{AG}$ & $\mathrm{CP}$ & $\mathrm{DM}$ & FE & FO & MA & SV & VS \\
\hline 2000 & 5,8125 & 23,25 & 304,812 & 8,875 & 281,188 & 3,25 & 6,3125 & 4,625 \\
\hline 2001 & 1,75 & 17,6875 & 363,125 & 21,125 & 76,0625 & 1,0625 & 1,9375 & 1,375 \\
\hline 2002 & 14 & 43,375 & 1022,125 & 14,0625 & 229,0625 & 4,625 & 21,6875 & 2,25 \\
\hline 2003 & 2,5625 & 32,0625 & 737,3125 & 28,875 & 142,5625 & 8,3125 & 13,3125 & 0,625 \\
\hline 2004 & 1,9375 & 90,8125 & 1776,25 & 40,8125 & 436,1875 & 3,9375 & 19,75 & 2 \\
\hline 2005 & 3,5 & 57,375 & 1155,375 & 33,375 & 187,8125 & 3,3125 & 17,8125 & 2,375 \\
\hline 2006 & 1,5 & 46,8125 & 1091,75 & 30 & 163,6875 & 6,1875 & 20,125 & 0,3125 \\
\hline 2007 & 7,75 & 34,625 & 797,5 & 36,6875 & 181,875 & 15,875 & 14,4375 & 0,125 \\
\hline 2008 & 21,5625 & 69,375 & 1398,189 & 89,6875 & 359,937 & 4,375 & 62,75 & 3,625 \\
\hline 2009 & 1,3125 & 40,9375 & 549,125 & 226,3745 & 319,625 & 3,5625 & 191,9375 & 0,75 \\
\hline 2010 & 6,625 & 16,0625 & 1006,4365 & 13,1875 & 184 & 2,5625 & 9,625 & 0,8125 \\
\hline 2011 & 1,6875 & 54,625 & 543,562 & 37,125 & 252,375 & 3,6875 & 14,5 & 1,0625 \\
\hline 2012 & 1,4375 & 9,3125 & 1040,5005 & 27,625 & 223,6875 & 5,0625 & 5,125 & 1,25 \\
\hline 2013 & 3,5625 & 28,9375 & 722,937 & 23,0625 & 293,5615 & 0,9375 & 16,1875 & 0,5 \\
\hline 2014 & 1,3125 & 19,1875 & 1966,9365 & 59,875 & 499,187 & 5,0625 & 16,5625 & 15,5625 \\
\hline
\end{tabular}

Notas: Agricultura (AG), Campinarana (CP), Desmatamento Acumulado até o Ano (DM),

Floresta Estacional (FE), Floresta Ombrófila (FO), Massa d'água (MA), Savana (SV) e Vegetação Secundária (VS).

A classe de corpo d'água apresentou alguns erros, a inclusão dessa classe como queimada ocorreu principalmente devido à resolução espacial do sensor MODIS e alguns resíduos que persistiram após a filtragem e normalização.

O coeficiente de correlação não demonstrou grande relação entre as taxas anuais de desmatamento e as taxas de queimadas, o valor obtido de $\mathrm{r}^{2}=0,2454$ indica que ou em grande parte das áreas desmatadas não houve utilização do fogo como forma de manejo, ou que parte das queimadas ocorreu em áreas de mata nativa onde não houve a posterior supressão vegetal. 


\subsection{Queimadas em Áreas Protegidas}

As áreas com diferentes tipos de uso antrópico também apresentaram padrões de queimadas diferenciados (Figura 13). A região de propriedades privadas ou sem título definido e que não possuem a direta intervenção do poder público somam $24358,8 \mathrm{Km}^{2}$ da área de estudo e correspondem às áreas onde foram identificadas as maiores taxas de queimadas. Em média $899 \mathrm{Km}^{2}$ são queimados todos os anos e estas queimadas estão basicamente relacionadas com a manutenção das pastagens e agricultura das propriedades rurais.

A Floresta Nacional do Jamanxim com área de 12202,20 $\mathrm{Km}^{2}$, isolada das outras unidades de conservação, teve a maior media de área queimada anualmente (média de 166 $\mathrm{km}^{2} / \mathrm{ano}$ ) dentre as regiões com intervenção do poder público. As Terras Indígenas, com 7524 $\mathrm{km}^{2}$ inseridos na área em estudo, apresentaram baixas taxas de queimadas ao longo da série histórica (média 7 km²/ano), localizadas nas bordas das Terras Indígenas, o que indica a predominância de focos de incêndios iniciados no exterior destas áreas.

Os assentamentos da reforma agrária, proporcionalmente à sua área, apresentaram a segunda e terceira posição em relação à área queimada anualmente, atrás apenas das Terras Particulares que em média tiveram $4 \%$ da sua área queimada. Os projetos de assentamentos de Desenvolvimento Sustentável (PDS) registraram a segunda maior proporção de área queimada com 3\% queimados anualmente e os Projetos de Assentamentos Tradicionais (PA) ocupam a terceira posição com $2 \%$ da área queimada anualmente.

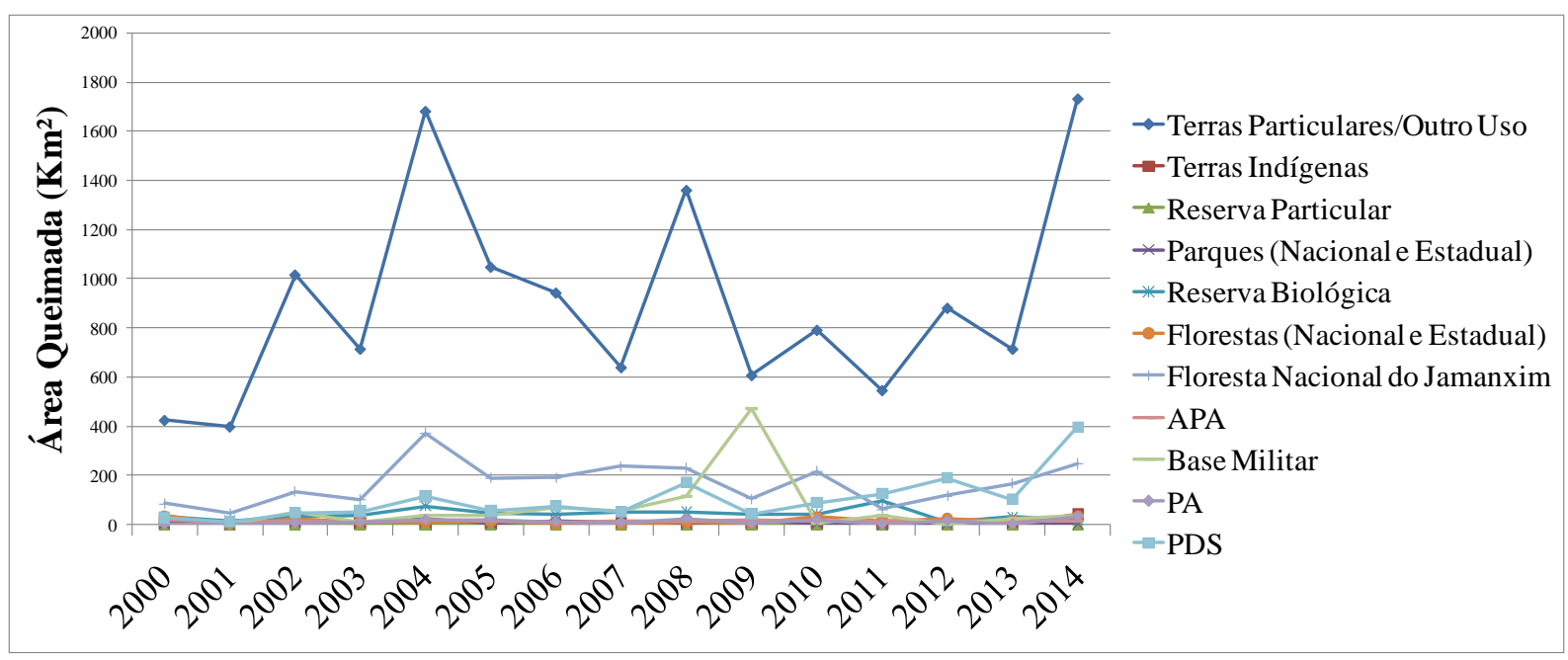

Figura 13: Queimadas Anuais por Tipo de Gestão. 
As unidades de conservação ambiental que incluem a Reserva Biológica, Parques, Florestas e Área de Preservação Ambiental (APA) e a Base Militar, apresentaram na média histórica de baixa incidência de queimadas. O Parque Nacional e o Estadual, levando-se em consideração a eficácia na prevenção de queimadas, são mais indicados por apresentarem taxas menores do que a Floresta Nacional e a Estadual, a Reserva Biológica e a Área de Proteção Ambiental (APA). Na Reserva Particular foram detectados os mais baixos níveis de queimadas em todos os anos, menos de $1 \mathrm{Km}^{2}$ de sua área foi queimada anualmente. Picos expressivos em alguns anos foram verificados na Base Militar em áreas de vegetação rasteiras, porém devido à baixa ocorrência de queimadas nos outros anos, a média de queimadas anuais na área é de $65 \mathrm{Km}^{2}$.

\subsection{Validação do Mapeamento e Comparação de dados}

O mapeamento de áreas queimadas pelas imagens MODIS foi validado com o mapeamento visual de duas imagens Landsat TM (28 de Julho de 2003 e 10 de Agosto de 2008). A tabela 4 lista os resultados dos coeficientes Kappa, acurácia geral, erros de comissão e omissão, considerando os diferentes procedimentos testados. O melhor resultado obtido adotou a seguinte combinação: banda do Infravermelho Próximo, imagens diárias e normalização pela média, possuindo valor do coeficiente Kappa de 0,72, erro de Comissão Inferiores de $16 \%$ e erro de Omissão de $36 \%$.

Em todos os testes, as imagens diárias apresentaram melhores resultados do que as imagens com composições de 8 dias. As composições de 8 dias auxiliam na redução de ruídos e efeitos atmosféricos ao selecionar o pixel de melhor qualidade, porém proporciona a perda de informação das áreas queimadas. Como esta área está em constante alteração, há perda de informações dentro dos 8 dias, apresentando impactos na detecção de áreas queimadas, portanto as imagens diárias apresentaram melhor resultado neste estudo. A aplicação dos índices NDVI, NBR e NBRT não melhorou a capacidade de mapeamento em relação à banda 2 do MODIS.

Tabela 4: Coeficiente de Kappa e Acurácia Geral do Mapeamento (Áreas Queimadas MODIS x Áreas Queimadas ETM+/TM).

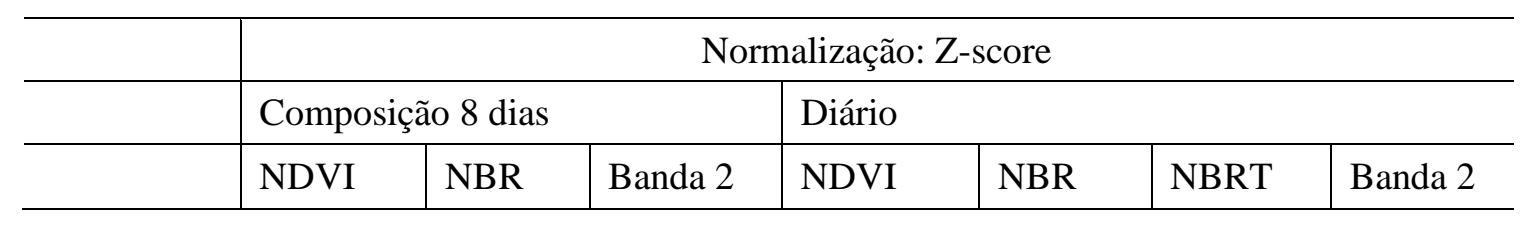




\begin{tabular}{|c|c|c|c|c|c|c|c|}
\hline $\begin{array}{l}\text { Acurácia } \\
\text { Geral }\end{array}$ & $92,96 \%$ & $97,58 \%$ & $99,10 \%$ & $96,14 \%$ & $98,58 \%$ & $69,65 \%$ & $99,43 \%$ \\
\hline Kappa & 0,1412 & 0,23325 & 0,54375 & 0,20735 & 0,2764 & 0,03565 & 0,68945 \\
\hline $\begin{array}{l}\text { Erros de } \\
\text { Comissão }\end{array}$ & 89,19 & 78,34 & 45,925 & 84,385 & 71,1 & 97,19 & 24,08 \\
\hline \multirow{4}{*}{$\begin{array}{l}\text { Erros de } \\
\text { Omissão }\end{array}$} & 55,15 & 66,355 & 43,21 & 57,94 & 72,105 & 12,105 & 36,14 \\
\hline & \multicolumn{7}{|c|}{ Normalização: Média } \\
\hline & \multicolumn{3}{|c|}{ Composição 8 dias } & \multicolumn{4}{|l|}{ Diário } \\
\hline & NDVI & NBR & Banda 2 & NDVI & NBR & NBRT & Banda 2 \\
\hline $\begin{array}{l}\text { Acurácia } \\
\text { Geral }\end{array}$ & $96,65 \%$ & $98,22 \%$ & $99,21 \%$ & $97,97 \%$ & $99,10 \%$ & $98,98 \%$ & $99,51 \%$ \\
\hline Kappa & 0,24055 & 0,3893 & 0,6012 & 0,37505 & 0,5367 & 0,4631 & 0,7238 \\
\hline $\begin{array}{l}\text { Erros de } \\
\text { Comissão }\end{array}$ & 69,04 & 56,605 & 40,26 & 58,47 & 37,825 & 46,015 & 15,84 \\
\hline $\begin{array}{l}\text { Erros de } \\
\text { Omissão }\end{array}$ & 58,98 & 51,41 & 37,075 & 55,875 & 50,54 & 57,325 & 36,015 \\
\hline
\end{tabular}

O produto MODIS de mapeamento de cicatrizes de queimadas (MCD45) tem sido utilizado amplamente, porém ainda necessita de aprimoramentos (MOUILLOT et al., 2014). Este produto foi validado na África utilizando como base imagens Landsat e obteve uma média de erros de comissão de $34 \%$ e omissão de 59\% (ROY \& BOSCHETTI, 2009). Recentemente, o produto MCD45 foi avaliado a nível global, contendo erros de comissão de $46 \%$ e omissão de $72 \%$, onde alguns biomas apresentaram resultados mais satisfatórios do que em outros, como nas Florestas Boreais e Savanas Tropicais e Subtropicais (PADILLA et al., 2014).

A tabela 5 lista o coeficiente Kappa entre o mapeamento de referência (Imagens Landsat-TM de 2003, 2008 e 2010) e do produto MCD45 para o mesmo mês. Observaram-se taxas de omissão superiores a 70\% e Kappa inferior a 0,35. 
Tabela 5: Coeficiente de Kappa e Acurácia Geral do Mapeamento (Áreas Queimadas MCD45 x Áreas Queimadas TM).

\begin{tabular}{l|l|l|l|l}
\hline $\begin{array}{l}\text { Data } \\
\text { (Landsat) }\end{array}$ & $\begin{array}{l}\text { Acurácia } \\
\text { Geral }\end{array}$ & $\begin{array}{l}\text { Coeficiente } \\
\text { Kappa }\end{array}$ & $\begin{array}{l}\text { Erros } \\
\text { comissão }\end{array}$ & de \\
\hline $28 / 07 / 2003$ & $99.3702 \%$ & 0.3500 & $35.88 \%$ & $75.69 \%$ \\
\hline $10 / 08 / 2008$ & $98.6897 \%$ & 0.2306 & $49.65 \%$ & $84.65 \%$ \\
\hline $01 / 09 / 2010$ & $96.9144 \%$ & 0.3026 & $8.56 \%$ & $81.23 \%$ \\
\hline
\end{tabular}

A Tabela 6 lista os valores do coeficiente Kappa entre o melhor método obtido nesta pesquisa (Imagens diárias do Infravermelho Próximo com Normalização por Média) com o mapeamento de cicatrizes de queimadas MCD45 v5.1. A partir da série temporal utilizada de 2003, 2008 e 2010 percebeu-se a baixa relação entre os dois métodos com média de Coeficiente Kappa de 0,29, muitas áreas não são classificadas como queimadas no MCD45 resultando em erros de omissão superiores a $75 \%$.

Tabela 6: Coeficiente Kappa e Acurácia Geral do Mapeamento (Áreas Queimadas MCD45 X Áreas Queimadas Método Proposto)

\begin{tabular}{c|c|c|c|c}
\hline $\begin{array}{c}\text { Período } \\
\text { (MCD45) }\end{array}$ & Acurácia Geral & $\begin{array}{c}\text { Coeficiente de } \\
\text { Kappa }\end{array}$ & $\begin{array}{c}\text { Erros de } \\
\text { Comissão }\end{array}$ & $\begin{array}{c}\text { Erros de } \\
\text { Omissão }\end{array}$ \\
\hline Julho de 2003 & $99.4238 \%$ & 0.2626 & 51.25 & 81.81 \\
\hline Agosto de 2008 & $99.0485 \%$ & 0.2793 & 52.11 & 79.89 \\
\hline $\begin{array}{c}\text { Setembro de } \\
2010\end{array}$ & $97.5119 \%$ & 0.3514 & $9.57 \%$ & 77.64 \\
\hline
\end{tabular}

A Figura 14 exemplifica a área mapeada com o método proposto, o mapeamento obtido a partir do produto MCD45 e a imagem Landsat TM com exemplo de áreas queimadas. Pode-se perceber que o método proposto consegue delimitar a maioria das áreas queimadas na imagem Landsat TM, porém devido à diferença de resolução dos sensores as menores queimadas não podem ser classificadas. Alguns pixels erroneamente classificados dentro de áreas de florestas que não foram queimadas também podem ser verificados. O produto MCD45 apresenta baixos erros de comissão, porém apresenta alta taxa de erros de omissão resultando em poucas áreas identificadas como queimadas. 


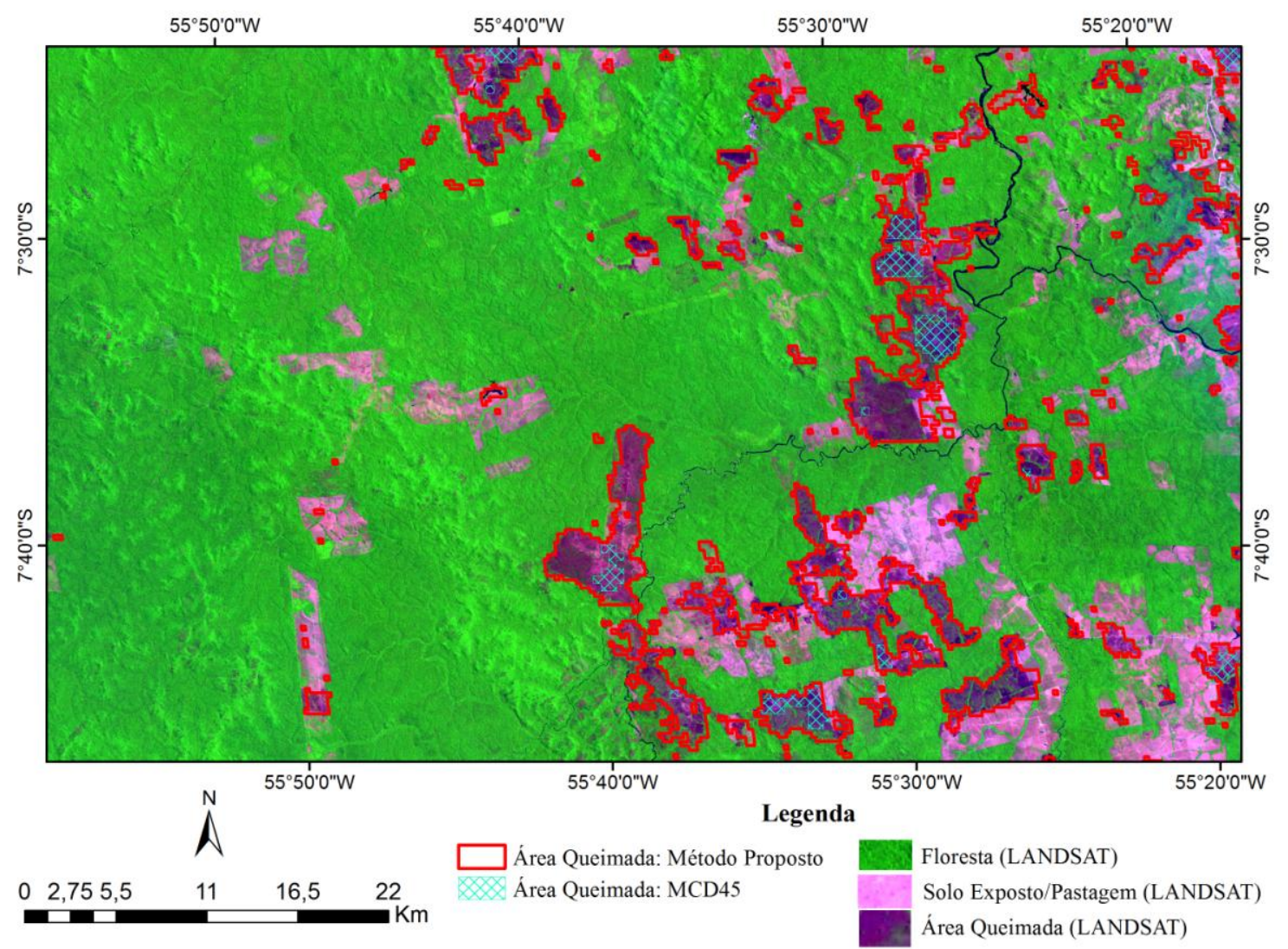

Figura 14: Comparação do Mapeamento de Queimadas: Método Proposto, MCD45 e Landsat/TM.

A comparação entre as áreas queimadas e os focos de incêndio processados no INPE (Figura 15) demonstrou a baixa quantidade de focos corretamente localizados dentro das áreas queimadas. Utilizou-se a média de focos da série de 2000 a 2014 e calculou-se a porcentagem de quantos focos por satélite se localizaram dentro de um pixel queimado para o método proposto nesta pesquisa.

Os satélites AQUA e TERRA foram os únicos, dentre os estudados, que apresentaram acerto maior que $30 \%$. Os focos dos satélites AQUA e TERRA foram utilizados para calcular o Coeficiente de Correlação entre o total de focos por ano e o total de área queimada anualmente, obteve-se 0,69 de correlação.

Esta dificuldade já foi apontada por Hantson et al. (2013) que observaram uma alta taxa de erros de comissão em áreas de Florestas com $u m \mathrm{R}^{2}=0,58$ calculado entre área total queimada e total de focos ativos. Nas áreas de pastagem os autores encontraram uma alta correlação $\left(R^{2}=0,82\right)$ entre total de focos ativos e área total queimada. 
Percebe-se que as áreas mapeadas como queimadas obtiveram uma média de $70 \%$ de acerto com a comparação entre mapeamento visual nas Imagens Landsat e entre os focos de incêndio, atestando a utilidade do método para detecção de áreas queimadas na Amazônia.

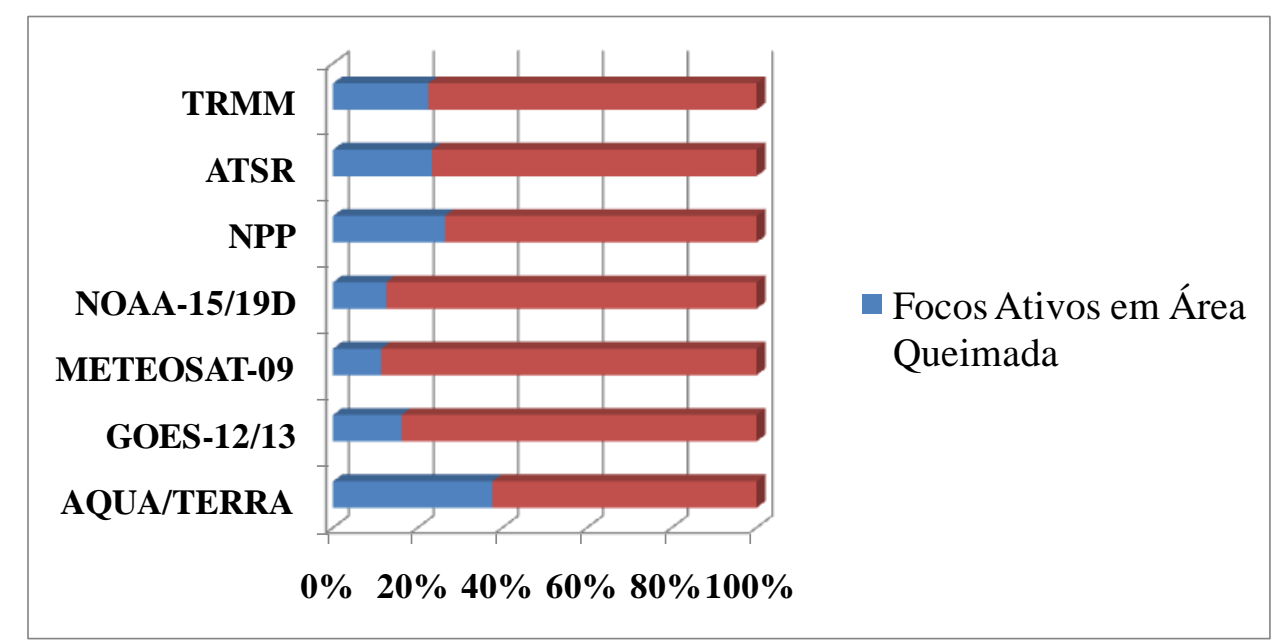

Figura 15: Focos de Incêndio Ativos, Detectados por Satélite, Localizados em Pixels Queimados. 


\section{DISCUSSÃO}

A presente pesquisa demonstrou a utilidade das séries temporais MODIS para o mapeamento das áreas queimadas em áreas de Floresta Amazônica. A necessidade do préprocessamento das imagens, em especial a filtragem dos dados, é uma etapa importante para o trabalho na região Amazônica, pois a grande presença de nuvens na região dificulta a seleção de imagens e mesmo aquelas sem nuvens possuem grande quantidade de aerossóis na época seca. (PEREIRA, 2003; CHEN et al., 2004; SAKAMOTO et al., 2005).

A aplicação da normalização temporal demonstrou resultados diferentes daqueles apontados por Carvalho Júnior et al. (2015) que identificaram a eficácia do Z-Score para separação de áreas queimadas em vegetação de savana. A aplicação deste método em áreas de Floresta Tropical gerou ruídos na série que reduziram a qualidade do mapeamento, principalmente relacionados a sombras de nuvens, portanto indica-se a utilização da normalização por média que apresentou melhores resultados.

A média de Kappa foi superior para as imagens diárias, este melhor resultado já foi abordado por outros autores que identificaram uma pequena vantagem das imagens diárias (CHEN et al., 2013; CHUVIECO et al., 2005) e pode ser explicado pelo processo de criação das composições de 8 dias, com a aquisição do "melhor pixel" dentre os 8 dias, o resultado gera uma imagem com alta qualidade porém algumas informações são perdidas. Já as imagens diárias podem preservar essas informações, mas necessitarão de um tratamento de ruídos mais abrangente e maior tempo de processamento devido à maior quantidade de imagens. Portanto dependendo do objetivo de cada pesquisa, em certos casos a utilização das composições de 8 dias, mesmo apresentando um resultado pior do que as diárias, traz mais benefícios já que o número de imagens e tempo de processamento serão menores.

O Kappa para os índices NBR, NBRT e NDVI demonstrou que estes possuem menor capacidade de separação de áreas queimadas do que a banda do Infravermelho Próximo, a principal explicação para este resultado deriva da própria criação dos índices, que foram gerados para aplicação em biomas como Florestas Temperadas e Tundras. Roy et al. (2006) alertaram sobre a ineficácia do NBR para mensurar a severidade de queimadas em florestas tropicais, além do observado pelos autores, a constante alteração na paisagem amazônica inviabiliza as técnicas de obtenção da severidade da queimada com a utilização de imagens de anos diferentes, já que em um mesmo mês há mudanças significativas na Floresta que poderiam interferir no resultado do índice. 
Diferente de Holden et al., (2005) e Harris et al., (2011) o índice NBRT não apresentou vantagens em relação ao índice NBR, o tamanho de pixel de $1 \mathrm{~km}$ do produto de temperatura pode ter influenciado neste resultado já que outros autores relatam a eficácia das bandas termais para análises de áreas queimadas (LIBONATI et al., 2010; QUINTANO et al., 2015), salientando que as interferências atmosféricas podem ser minimizadas com a utilização de canais termais. Porém devido a resolução espacial das imagens termais MODIS há uma grande degradação das áreas, dificultando um mapeamento com melhor precisão do que utilizando as imagens do infravermelho próximo com resolução de 250 metros.

Como observado pela estatística de Kappa para os diferentes métodos testados, a utilização da banda do infravermelho próximo trouxe a maior separabilidade entre área queimada e não queimada, Pleniou \& Koutsias (2013) e Alonso-Canas \& Chuvieco (2015) também se utilizaram desta região do espectro para separação das áreas queimadas e obtiveram resultados satisfatórios. Deve-se, no entanto, atentar-se que sombras de nuvens e a água têm respostas semelhantes á queimada no Infravermelho Próximo, portanto deve-se utilizar algum procedimento de normalização ou máscaras para evitar falsos positivos.

Outros trabalhos como Quintano et al. (2011), Cardozo et al. (2014), também se utilizaram de séries temporais MODIS para o mapeamento de áreas queimadas, as diferentes metodologias de mapeamento de queimadas, a partir do sensor MODIS, foram testadas e conseguiram separar as áreas queimadas em diversos biomas incluindo-se a Amazônia. Os principais problemas encontrados nos trabalhos foram relacionados à qualidade da resolução espacial do sensor que dificulta o mapeamento de queimadas em pequenas áreas.

$\mathrm{Na}$ metodologia apresentada perceberam-se algumas limitações quanto ao mapeamento de área queimada na Floresta Amazônica utilizando apenas o Infravermelho Próximo. Mesmo com os procedimentos de normalização e filtragem temporal, as sombras de nuvens ainda apresentam características semelhantes a da vegetação queimada, o que impede a utilização de imagens com grande quantidade de nuvens.

Para avaliar a utilidade da metodologia apresentada, foi realizada a comparação dos pixels queimados com o tipo de vegetação e tipo de ocupação da terra. $\mathrm{O}$ tipo de cobertura do solo mais afetado pelas queimadas foram as áreas desmatadas, isto é explicado principalmente por que nesta região o fogo é utilizado para a manutenção de áreas de pastagens, em períodos regulares há a necessidade de se queimar novamente a pastagem para combater plantas invasoras, pragas e melhorar a baixa produtividade do solo (NEPSTAD, 1999), a dificuldade de acesso a alternativas viáveis de manejo da agropecuária da região também é um fator importante para explicar as altas taxas de queimadas (MENDONÇA et al., 2004). 
Nas áreas onde a queimada ocorreu apenas 1 ano na série histórica, em geral predomina-se fogo em mata nativa, quando algum foco de incêndio foge do controle dos produtores, há a possibilidade de avanço para as áreas fragmentadas da florestas que já apresentam alta vulnerabilidade a queimadas (COCHRANE, 2001; COCHRANE et al., 2002).

As áreas protegidas apresentaram padrões diferenciados de queimadas, as reservas particulares e áreas indígenas representaram as áreas com menor influência, destacando que a gestão destas áreas tem sido eficaz para a preservação ambiental, já as áreas de uso particular e a Floresta Nacional do Jamanxim foram as responsáveis pela maior ocorrência de queimadas, neste caso questões históricas como a ocupação da Floresta Nacional do Jamanxim são as responsáveis pelos altos índices de queimadas.

Nepstad et al. (2006) demonstraram a importância das áreas protegidas na Amazônia para a prevenção do desmatamento e das queimadas, os autores identificaram que os Parques Indígenas são a principal barreira para o desmatamento e aliados aos Parques Nacionais são os com menor influência do fogo. Já Nelson \& Chomitz (2011) identificaram que as unidades de uso sustentável e as Terras Indígenas são de grande relevância para a preservação da Floresta, porém no caso da área de estudo, a Floresta Nacional e a Estadual e a Área de Preservação Ambiental por terem um regime mais flexível que permite a utilização dos seus recursos, não se mostraram grandes barreiras para a propagação dos incêndios.

A comparação entre o produto de mapeamento de queimadas MCD45 e o mapeamento de referência, demonstrou a inviabilidade da utilização deste produto nesta área específica, já que grande parte das áreas queimadas não são identificadas. A resolução do produto de 500 metros influenciou na diferença significativa entre os dois métodos, porém também percebese que a aplicação de algoritmos de mudanças sazonais na região de Floresta Amazônica tem limitações, devido a constante alteração da paisagem. Para outras regiões tropicais também já foi comprovado por Libonati et al. (2015), que a metodologia utilizada pelo produto MCD45 apresenta altos índices de erros de Omissão

Para a comparação entre os focos de incêndio ativos e o mapeamento proposto obtevese um resultando semelhante ao de Hantson et al. (2013) levando-se em conta a presença de floresta e de pastagem na área de estudo, há a ocultação de muitos focos devido a intensa cobertura de nuvens da região e falsos alertas resultando em uma média de $30 \%$ de focos corretamente localizados em áreas queimadas. 


\section{CONCLUSÕES}

Este estudo avaliou a aplicação de uma metodologia automática para o mapeamento de áreas queimadas na Floresta Amazônica a partir de séries temporais do sensor MODIS. A utilização de séries temporais é uma das alternativas para mapear os eventos de queimadas em uma região com intensa cobertura de nuvens. Imagens com baixa resolução temporal como as dos satélites Landsat, apesar de possuírem maior acurácia apresentam limitações em certos períodos do ano.

Para aplicação da metodologia foram selecionadas diferentes séries temporais do sensor MODIS que englobaram a banda do Infravermelho Próximo e os índices NBR, NBRT e NDVI em séries diárias e de 8 dias, e o índice NBRT em séries diárias.

Foi considerada a utilização de mapeamento nas imagens Landsat como verdade terrestre e aplicou-se coeficientes de Kappa para verificar os melhores valores de reflectância a serem utilizados nas imagens MODIS para a diferenciação entre área queimada e não queimada. Dentre os testes realizados percebeu-se a necessidade de aplicação de filtros temporais para reduzir os ruídos e efeitos atmosféricos e a aplicação de normalização dos diferentes valores de reflectância para padronizar a série e permitir a separação de alvos.

A comparação das composições padrão de 8 dias e das imagens diárias mostrou que as imagens diárias alcançam um melhor Kappa, apesar de a composição de 8 dias apresentar menos ruídos, algumas informações são perdidas ao se escolher um pixel representativo dos 8 dias, como a região amazônica é marcada por mudanças bruscas e rápidas na paisagem, as imagens diárias retratam melhor esses padrões.

Diferente de pesquisas realizadas em outros biomas, a aplicação dos índices NBR, NDVI e NBRT não apresentou bons resultados nesta área de estudo. Existe muita semelhança entre as áreas desmatadas e as áreas queimadas o que compromete a acurácia do mapeamento, portanto recomenda-se a utilização da banda espectral do Infravermelho Próximo para a detecção de áreas queimadas nesta região.

As áreas queimadas foram comparadas com tipo de floresta e tipo de gestão do solo, atestando que, nesta região, as áreas desmatadas são as responsáveis por mais de $70 \%$ das queimadas anualmente, e algumas barreiras a estes processos são as Reservas Ambientais Particulares e as Terras Indígenas que apresentaram baixa proporção de queimadas.

Esta metodologia pode ser útil e de fácil aplicação para o mapeamento de áreas queimadas em áreas de floresta tropical e apesar de possuir uma média de Kappa de 0,72, conseguiu-se um resultado superior ao disponibilizado pelo produto MCD45. O 
aprimoramento de métodos para o monitoramento das áreas queimadas na Amazônia poderá auxiliar na gestão e manejo do fogo na região e auxiliar nas estimativas dos impactos gerados por ele. 


\section{REFERÊNCIAS BIBLIOGRÁFICAS}

ABADE, N. A.; CARVAlHO JÚNIOR, O. A.; GUIMARÃES, R. F.; OLIVEIRA, S. A. Comparative Analysis of MODIS Time-Series Classification Using Support Vector Machines and Methods Based upon Distance and Similarity Measures in the Brazilian Cerrado-Caatinga Boundary. Remote Sensing, v. 7, n. 9, p. 12160-12191, 2015.

ALENCAR, A.; BRANDO, P. M.; ASNER, G. P.; PUTZ, F. E. Landscape fragmentation, severe drought and the new Amazon forest fire regime. Ecological Applications, v.25, n. 6, p. 1493-1505, 2015.

ALENCAR, A.; NEPSTAD, D.; DIAZ, M.C.V. Forest understory fire in the Brazilian Amazon in ENSO and non-ENSO years: area burned and committed carbon emissions. Earth Interactions, v. 10, n. 6, p. 1-17, 2006.

ALENCAR, A.A.; BRANDO, P.M.; ASNER, G.P.; PUTZ, F.E. Landscape fragmentation, severe drought, and the new Amazon forest fire regime. Ecological applications, v. 25, n. 6, p. 1493-1505, 2015.

ALONSO-CANAS, I.; CHUVIECO, E. Global burned area mapping from ENVISAT-MERIS and MODIS active fire data. Remote Sensing of Environment, v. 163, p. 140-152, 2015.

ARAGÃO, L.E.O.C.; MALHI, Y.; ROMAN-CUESTA R.M.; SAATCHI S.S.; ANDERSON L.O.; SHIMABUKURO Y.E. Spatial patterns and fire response of recent Amazonian droughts. Geophysical Research Letters, v. 34, 2007.

ARAÚJO, F. M.; FERREIRA, L. G.; ARANTES, A. R. Distribution Patterns of Burned Areas in the Brazilian Biomes: An Analysis Based on Satellite Data for the 2002-210 Period. Remote Sensing, v. 4, p. 1929-1946, 2012.

ARAÚJO, H. J. B.; OLIVEIRA, L. C.; VASCONCELOS, S. S.; CORREIA, M. F. Danos provocados pelo fogo sobre a vegetação natural em uma floresta primária no estado do Acre, Amazônia brasileira. Ciência Florestal, v. 23, n. 2, p. 297-308, 2013.

ARMENTERAS, D.; RETANA, J. Dynamics, patterns and causes of fires in Northwestern Amazonia.PloS one, v. 7, n. 4, e35288, 2012.

ATAMAN, E.; AATRE, V. K.; WONG, K. M. Some Statistical Properties of Median Filters.IEEE Transactions on Acoustics, Speech, and Signal Processing, v. 29, n. 5, p. 1073-1075, 1981.

AYANS, J. S. M.; RAVAIL, N.; KELHA, V.; OLLERO, A. Active Fire Detection for Fire Emergency Management: Potential and limitations for the operational use of Remote Sensing. Natural Hazards, v. 35, p. 361-376, 2005.

BARBOSA, P. M.; PEREIRA, J. M. C.; GRÉGOIRE, J. M. Compositing Criteria for Burned Area Assessment Using Multitemporal Low Resolution Satellite Data.Remote Sensing of Environment, v. 65, p.38-49, 1998.

BASTARRIKA, A.; CHUVIECO, E.; MARTÍN, M. P. Automatic Burned Land Mapping from MODIS Time Series Images: Assessment in Mediterranean Ecosystems. IEEE Transactions on Geoscience and Remote Sensing, v. 49, n. 9, p. 3401- 3413, 2011. 
BENTO-GONÇALVES, A.; VIEIRA, A.; ÚBEDA, X.; MARTIN, D. Fire and soils: Key concepts and recent advances.Geoderma, v. 191, p. 3-13, 2012.

BOWMAN, D. M. J. S.; BALCH, J. K.; ARTAXO, P.; BOND, W. J.; CARLSON, J. M.; COCHRANE, M. A.; D'ANTONIO, C. M.; DEFRIES, R. S.; DOYLE, J. C.; HARRISON, S. P.; JOHNSTON, F. H.; KEELEY, J. E.; KRAWCHUK, M. A.; KULL, C. A.; MARSTON, J. B.; MORITZ, M. A.; PRENTICE, I. C.; ROOS, C. I.; SCOTT, A. C.; SWETNAM, T. W.; van der WERF, G. R.; PYNE, S. J. Fire in the Earth System.Science, v. 324, p. 481-484, 2009.

BUSH, M. B.; SILMAN, M. R.; MCMICHAEL, C.; SAATCHI, S. Fire, climate change and biodiversity in Amazonia: a Late-Holocene perspective.Philosophical Transactions of the Royal Society of London, Series B, v. 363, p. 1795-1802, 2008.

CANO-CRESPO, A.; OLIVEIRA, P.J.; BOIT, A.; CARDOSO, M.; THONICKE, K. Forest edge burning in the Brazilian Amazon promoted by escaping fires from managed pastures. Journal of Geophysical Research: Biogeosciences, v. 120, n. 10, p. 2095-2107, 2015.

CARDOZO, F. S.; PEREIRA, G.; SHIMABUKURO, Y. E.; MORAES, E. C. Avaliação das Áreas Queimadas no Estado de Rondônia-Amazônia Brasileira.Revista Brasileira de Cartografia, n. 66 (3), p.705-716, 2014.

CARDOZO, F.D.S.; PEREIRA, G.; SHIMABUKURO, Y.E.; MORAES, E.C. Validation of MODIS MCD45A1 Product to identify burned areas in Acre State-Amazon Forest. In: IEEE International Geoscience and Remote Sensing Symposium (IGARSS), p. 6741-6744. 2012.

CARVALHO JÚNIOR, O. A.; GUIMARÃES, R. F.; SILVA, C. R.; GOMES, R. A. T. Standardized Time-Series and Interannual Phenological Deviation: New Techniques for Burned-Area Detection Using Long-Term MODIS-NBR Dataset. Remote Sensing, v. 7, p. 6950-6985, 2015.

CARVALHO JÚNIOR, O. A.; SAMPAIO, C. S.; SILVA, N. C.; COUTO JÚNIOR, A. F.; GOMES, R. A. T.; CARVALHO, A. P. F.; SHIMABUKURO, Y. E. Classsificação de padrões de savana usando assinaturas temporais NDVI do sensor MODIS no Parque Nacional Chapada dos Veadeiros. Revista Brasileira de Geofísica,n. 26, n. 4, p. 505-517, 2008.

CARVALHO JÚNIOR, O. A.; SILVA, N. C.; CARVALHO, A. P. F.; COUTO JÚNIOR, A. F.; SILVA, C. R.; SHIMABUKURO, Y. E.; GUIMARÃES, R. F.; GOMES, R. A. T. Combining Noise-Adjusted Principal Componentes Transform and Median Filter techniques for denoising MODIS temporal signatures.Revista Brasileira de Geofísica, v. 30, n. 2, p. 147-157, 2012.

CERTINI, G. Effects of fire on properties of Forest soils: a review. Oecologia, v. 143, p.1-10, 2005.

CHEN, J.; JONSON, P.; TAMURA, M.; GU, Z.; MATSUSHITA, B.; EKLUNDH, L. A simple method for reconstructing a high-quality NDVI time-series data set based on the Savitzky-Golay filter. Remote Sensing of Environment, n. 91, p.332-344, 2004.

CHEN,Y.; HUANG, C.; TICEHURST, C.; MERRIN, L.; THEW, P. An Evaluation of MODIS Daily and 8-day Composite Products for Floodplain and Wetland Inundation Mapping.Wetlands, v. 33, p. 823-835, 2013. 
CHUVIECO, E.; MARTÍN, M. P.; PALACIOS, A. Assessment of different spectral indices in the red-near-infrared spectral domain for burned land discrimination.Internacional Journal of Remote Sensing, v. 23, n. 23, p. 5103-5110, 2002.

CHUVIECO, E.; MARTÍNEZ, S.; ROMÁN, M. V.; HANTSON, S.; PETTINARI, M. L. Integration of ecological and socio-economic factors to assess global vulnerability to wildfire. Global Ecology and Biogeography, v. 23, n. 2, p. 245-258, 2014.

CHUVIECO, E.; VENTURA, G.; MARTÍN, M. P. AVHRR multitemporal compositing techniques for burned land mapping.International Journal of Remote Sensing, v. 26, n.5, p.1013-1018, 2005.

COCHRANE, M. A. Synergistic Interactions between Habitat Fragmentation and Fire in Evergreen Tropical Forests.Conservation Biology,v.15, n. 6, p. 1515-1521, 2001.

COCHRANE, M. A.; LAURANCE, W. F. Fire as a large-scale edge effect in Amazonian forests. Journal of Tropical Ecology, v. 18, n. 3, p. 311-325, 2002.

COCHRANE, M. A.; SCHULZE, M. D. Fire as a Recurrent Event in Tropical Forests in Eastern Amazon: Effects on Forest Structure, Biomass, and Species Composition.Biotropica, v. 31, n. 1, p. 2-16, 1999.

CONGALTON, R.; GREEN, K. Assessing the Accuracy of Remotely Sensed Data: Principles and Practices; CRC/Lewis Press: Boca Raton, FL, USA, 1999.

COPPIN, P.; JONCKHEERE, I.; NACKAERTS, K.; MUYS, B.; LAMBIN, E. Digital change detection methods in ecosystem monitoring: a review. International Journal of Remote Sensing, v. 25, n. 9, p. 1565-1596, 2004.

CORNER, B. R.; NARAYANAN, R. M.; REICHENBACH, S. E. Noise estimation in remote sensing imagery using data masking. International Journal of Remote Sensing, v. 24, n. 4, p. 689-702, 2003.

COUTINHO, L. M. Fire in the Ecology of Brazilian Cerrado. In: Goldammer, J. G. (Ed.). Fire in the Tropical Biota: Ecosystems Processes and Global Challenges.Berlim, Springer-Verlag, 1990, p. 82-105.

COUTO JUNIOR, A. F.; CARVALHO JUNIOR, O. A.; MARTINS, E. S. Séries temporais de NDVI, EVI, e NDWI do sensor MODIS para caracterização fenológica do algodão. Revista Brasileira de Cartografia, n. 65, p. 1, p. 199-210, 2013.

DEMPEWOLF, J.; TRIGG, S.; DEFRIES, R. S.; EBY, S. Burned-Area Mapping of the Serengeti-Mara Region Using MODIS Reflectance Data. IEEE Geoscience and Remote Sensing Letters, v. 4, n. 2, p. 312-316, 2007.

DÍAZ-DELGADO, R.; LLORET, F.; PONS, X. Influence of fire severity on plant regeneration by means of remote sensing imagery.International Journal of Remote Sensing, v. 24, n. 8, p.1751-1763, 2003.

ESCUIN, S.; NAVARRO, R.; FERNÁNDEZ, P. Fire severity assessment by using NBR (Normalized Burn Ratio) and NDVI (Normalized Difference Vegetation Index) derived from LANDSAT TM/ETM images. International Journal of Remote Sensing, v. 29, n. 4, p. 1053-1073, 2008. 
EVA, H.; LAMBIN, E. F. Fire and land-cover change in the tropics: a remote sensing analysis at the landscape scale.Journal of Biogeography, v.27, n. 3, p. 765-776, 2000.

FANIN, T.; van der WERF, G. R. Relationships between burned area, forest cover loss, and land cover change in Brazilian Amazon based on satellite data. Biogeosciences, v. 12, n. 20, p. 6033-6043, 2015.

FEARNSIDE, P. M. Brazil's Cuiabá-Santarém (BR-163) Highway: The Environmental Cost of Paving a Soybean Corridor Through the Amazon. Environmental Management, v. 39, p. 601-614, 2007.

FERNANDES, K.; BAETHGEN, W.; BERNARDES, S.; DEFRIES, R.; DEWITT, D.G.; GODDARD, L.; LAVADO, W.; LEE, D.E.; PADOCH, C., PINEDO-VASQUEZ, M.; URIARTE, M.; URIARTE, M. North Tropical Atlantic influence on western Amazon fire season variability. Geophysical Research Letters, v. 38, n. 12, L12701, 2011.

Fundação Nacional do Índio (FUNAI). Mapas. 2015. Available Online:http://mapas2.funai.gov.br/ (acessed on 24 October 2015).

GIGLIO, L., van der WERF, G.R., RANDERSON, J.T., COLLATZ, G.J., KASIBHATLA, P. Global estimation of burned area using MODIS active fire observations. Atmospheric Chemistry and Physics, v. 6, p. 957-974, 2006b.

GIGLIO, L.; CSISZAR, I.; JUSTICE, C.O. Global distribution and seasonality of active fires as observed with the Terra and Aqua MODIS sensors. Journal of Geophysical Research, v. 111, 2006a.

GIGLIO, L.; LOBODA, T.; ROY, D. P.; QUAYLE, B.; JUSTICE, C. O. An active-fire based burned area mapping algorithm for the MODIS sensor. Remote Sensing of Environment, v. 113, p. 408-420, 2009.

GU, J.; LI, X.; HUANG, C.; OKIN, G. S. A simplified data assimilation method for reconstructing time-series MODIS NDVI data. Advances in Space Research, v. 44, n. 4, p. 501-509, 2009.

GUTIÉRREZ-VÉLEZ, V. H.; URIARTE, M.; DEFRIES, R.; PINEDO-VÁSQUEZ, M.; FERNANDES, K.; CECCATO, P.; BAETHGEN, W.; PADOCH, C. Land cover change interacts with drought severity to change fire regimes in Western Amazonia. Ecological Applications, v.24, n. 6,p. 1323-1340. 2014.

HANTSON, S.; PADILlA, M.; CORTI, D.; CHUVIECO, E. Strengths and weaknesses of MODIS hotspot to characterize global fire ocurrence. Remote Sensing of Environment, v. 131, p. 152-159, 2013.

HARDTKE, L. A.; BLANCO, P. D.; VALLE, H. F.; METTERNICHT, G. I.; SIONE, W. F. Semi-automated mapping of burned areas in semi-arid ecosystems using MODIS time-series imagery. International Journal of Applied Earth Observation and Geoinformation, v. 38, p. 25-35, 2015.

HARRIS, S.; VERAVERBEKE, S.; HOOK, S. Evaluating Spectral Indices for Assessing Fire Severity in Chaparral Ecosystems (Southern California) Using MODIS/ASTER (MASTER) Airbone Simulator Data. Remote Sensing,v. 3, n. 11, p. 2403-2419,2011. 
HIRD, J. N.; MCDERMID, G. J. Noise reduction of NDVI time series: An empirical comparison of selected techniques. Remote Sensing of Environment, v. 113, n. 1, p. 248$258,2009$.

HOLDEN, Z. A.; SMITH, A. M. S.; MORGAN, P.; ROLlinS, M. G.; GESSLER, P. E. Evaluation of novel thermally enhanced spectral indices for mapping fire perimeters and comparison with fire atlas data. International Journal of Remote Sensing, v. 26, n. 21, p. 4801-4808, 2005.

HUESCA, M.; LITAGO, J.; MERINO-DE-MIGUEL, S.; CICUENDEZ-LÓPEZ-OCANA, V.; PALACIOS-ORUETA, A. Modeling and forecasting MODIS-based Fire Potential Index on a pixel basis using time series models. International Journal of Applied Earth Observation and Geoinformation,v. 26, p. 363-376. 2014.

ICE, G. G.; NEARY, D. G.; ADAMS, P. W. Effects of Wildfire on Soils and Watershed Processes.Journal of Forestry, v. 102, n. 6, 16-20, 2004.

IGNOTTI, E.; VALENTE, J. G.; LONGO, K. M.; FREITAS, S. R.; HACON, S. S.; NETTO, P. A. Impact on human health of particulate matter emitted from burnings in the Brazilian Amazon region. Revista de Saúde Pública, v. 44, n. 1, p. 121-130, 2010.

INSTITUTO BRASILEIRO DE GEOGRAFIA E ESTATÍSTICA (IBGE). Mapa de Climas do Brasil. IBGE: Rio de Janeiro, Brasil, 2002.Disponível em: $<$ http://portaldemapas.ibge.gov.br> (Acesso em 23 Outubro 2015).

INSTITUTO BRASILEIRO DE GEOGRAFIA E ESTATÍSTICA (IBGE). Vegetação: Estado do Pará. IBGE: Rio de Janeiro, Brasil, 2008. Disponível em: <http://portaldemapas.ibge.gov.br> (Acesso em 23 Outubro 2015).

INSTITUTO CHICO MENDES DE CONSERVAÇÃO DA BIODIVERSIDADE (ICMBIO). Geoprocessamento. 2015. Disponível em: 〈http://www.icmbio.gov.br> (Acesso em 25 Outubro 2015).

INSTITUTO DO HOMEM E MEIO AMBIENTE DA AMAZÔNIA (IMAZON). Mapas Áreas Protegidas da Amazônia Legal. 2015. Disponível em: <http://imazon.org.br/> (Acesso em25 Outubro 2015).

INSTITUTO NACIONAL DE COLONIZAÇÃO E REFORMA AGRÁRIA (INCRA). Acervo Fundiário. 2015. Disponível em: <http://acervofundiario.incra.gov.br/> (Acesso em 25 Outubro 2015).

INSTITUTO NACIONAL DE METEOROLOGIA (INMET). Normais Climatológicas do Brasil. 2015. Disponível em:<http://www.inmet.gov.br> (Acesso em23 Outubro 2015).

INSTITUTO NACIONAL DE PESQUISAS ESPACIAIS (INPE). Monitoramento da Floresta Amazônica Brasileira por Satélite - Projeto PRODES. 2015a. Disponível em: $<$ http://www.obt.inpe.br/prodes/index.php> (Acesso em 25 Outubro 2015).

INSTITUTO NACIONAL DE PESQUISAS ESPACIAIS (INPE). Portal do Monitoramento de Queimadas e Incêndios. 2015b. Disponível em: <http://queimadas.cptec.inpe.br> (Acesso em: 22 Junho 2015). 
JACQUIN, A.; CHERET, V.; SHEEREN, D.; BALENT, G. Détermination du régime des feux en milieu de savane à Madagascar à partir de séries temporelles d'images MODIS.International Journal of Remote Sensing, v. 32, n. 24, p. 9219-9242, 2011.

JENSEN, J. R. Sensoriamento remoto do ambiente: uma perspectiva em recursos terrestres. São José dos Campos: Parêntese, 604 p. 2009.

JOLLY, W. M.; COCHRANE, M. A.; FREEBORN, P. H.; HOLDEN, Z. A.; BROWN, T. J.; WILLIAMSON, G. J.; BOWMAN, D. M. J. S. Climate-induced variations in global wildfire danger from 1979 to 2013. Nature Communications,v. 6, n. 7537, p. 1-11, 2015.

JUSTICE, C. O.; GIGLIO, L.; KORONTZI, S.; OWENS, J.; MORISETTE, J. T.; ROY, D.; DESCLOITRES, J.; ALLEAUME, S.; PETITCOLIN, F.; KAUFMAN, Y. The MODIS fire products. Remote Sensing of Environment, v. 83, n. 1-2, p. 244-262, $2002 \mathrm{a}$.

JUSTICE, C. O.; TOWNSHEND, J. R. G.; VERMOTE, E. F.; MASOUKA, E.; WOLFE, R. E.; SALEOUS, N.; ROY, D. P.; MORISETTE, J. T. An overview of MODIS Land data processing and product status. Remote Sensing of Environment, v. 83, p. 3-15, 2002b.

KASISCHKE, E. S.; FRENCH, N. H. F. Monitoring of wildfires in Boreal Forests using large area AVHRR NDVI composite image data. Remote Sensing of Environment, v. 45, n. 1, p. 61-71, 1993.

KAUFMAN, Y.J.; JUSTICE, C.O. 1998.MODIS Fire Products.Algorithm Technical Background Document. 77pp

KEY, C. H.; BENSON, N. C. Landscape Assessment: sampling and analysis methods.USDA Forest Service Gen. Tech. Rep. Rocky Mountain Research Station General Technical Report RMRS-GTR-164-CD. 2006.

KINOSHITA, A.M.; HOGUE, T.S. Spatial and temporal controls on post-fire hydrologic recovery in Southern California watersheds. Catena, v. 87, p. 240-252, 2011.

LANGMANN, B.; DUNCAN, B.; TEXTOR, C.; TRENTMANN, J.; van der WERF, G. R. Vegetation fire emissions and their impact on air pollution and climate. Atmospheric Environment, v. 43, n. 1, p. 107-116, 2009.

LAURANCE, W.F.; WILLIAMSON, G.B. Positive feedbacks among forest fragmentation, drought, and climate change in the Amazon, Conservation Biology, v. 15, p. 1529-1535, 2001.

LENTILE, L. B.; HOLDEN, Z. A.; SMITH, A. M. S.; FALKOWSKI, M. J.; HUDAK, A. T.; MORGAN, P.; LEWIS, S. A.; GESSLER, P. E.; BENSON, N. C. Remote sensing techniques to assess active fire characteristics and post-fire effects. International Journal of Wildland Fire, v. 15, p. 319-345, 2006.

LEWIS, S.L.; BRANDO, P.M.; PHILLIPS, O.L.; van der HEIJDEN, G.M.; NEPSTAD, D. The 2010 amazon drought. Science, v. 331, n. 6017, p. 554-554, 2011.

LI, R. R.; KAUFMAN, Y. J.; HAO, W. M.; SALMON, J. M.; GAO B.C. A Technique for Detecting Burn Scars Using MODIS Data.IEEE Transactions on Geoscience and Remote Sensing, v. 42, n. 6, p. 1300-1308, 2004. 
LI, W.; FU, R.; DICKINSON, R.E. Rainfall and its seasonality over the Amazon in the 21st century as assessed by the coupled models for the IPCC AR4, Journal of Geophysical Research, v. 111, 2006.

LIBONATI, R.; da CAMARA, C. C.; PEREIRA, J. M. C.; PERES, L. F. Retrieving middleinfrared reflectance for burned area mapping in tropical environments using MODIS. Remote Sensing of Environment, v. 4, n. 15, p. 831-843, 2010.

LIBONATI, R.; da CAMARA, C. C.; SETZER, A. W.; MORELlI, F.; MELCHIORI, A. E. An Algorithm for Burned Area Detection in the Brazilian Cerrado Using $4 \mu \mathrm{m}$ MODIS Imagery.Remote Sensing,v. 7, p. 15782-15803, 2015.

LIMA, A.; SILVA, T. S. F.; ARAGÃO, L. E. O. C.; FREITAS, R. M.; ADAMI, M.; FORMAGGIO, A. R.; SHIMABUKURO, Y. E. Land use and land cover changes determine the spatial relationship between fire and deforestation in the Brazilian Amazon. Applied Geography, v. 34, p. 239-246, 2012.

LOBODA, T.; O'NEAL, K. J.; CSISZAR, I. Regionally adaptable dNBR-based algorithm for burned area mapping from MODIS data. Remote Sensing of Environment, v. 109, n. 4, p. 429-442, 2007.

LOZANO, F. J.; SUÁREZ-SEOANE, S.; LUIS, E. Assessment of several spectral indices derived from multi-temporal Landsat data for fire ocurrence probability modelling. Remote Sensing of Environment, v. 107, n. 4, p. 533-544, 2007.

LUNNETA, R. S.; KNIGHT, J. F.; EDIRIWICKREMA, J.; LYON, J. G.; WORTHY, L. D. Land-cover change detection using multi-temporal MODIS NDVI data.Remote Sensing of Environment, v. 105, p. 142-154, 2006.

LUTZ, J. A.; KEY, C. H.; KOLDEN, C. A.; KANE, J. T.; WAGTENDONK, J. W. Fire Frequency, Area Burned, and Severity: A Quantitative Approach to Defining a Normal Fire Year. Fire Ecology, v. 7, n. 2, p. 51-65, 2011.

MAIER, S. W. Changes in surface reflectance from wildfires on the Australian continent measured by MODIS. International Journal of Remote Sensing, v. 31, n. 12, p. 3161-3176, 2010.

MARENGO, J. A.; NOBRE, C.A.; TOMASELLA, J.; OYAMA, M.D.; SAMPAIO DE OLIVEIRA, G.; DE OLIVEIRA, R.; CAMARGO, H.; ALVES, L.M.; BROWN, I. F. The drought of Amazonia in 2005. Journal of Climate, v. 21, n. 3, p. 495-516, 2008.

MARENGO, J.A. Interannual variability of surface climate in the Amazon basin, International Journal of Climatology, v. 12, p. 853- 863, 1992

MARENGO, J.A. Interdecadal variability and trends of rainfall across the Amazon basin, Theoretical and Applied Climatology, v. 78, n. 79- 96, 2004.

MARLON, J. R.; BARTLEIN, P. J.; DANIAU, A. L.; HARRISON, S. P.; MAEZUMI, S. Y.; POWER, M. J.; TINNER, W.; VANNIÉRE, B. Global biomass burning: a synthesis and review of Holocene paleofire records and their controls. Quaternary Science Reviews, v. 65, p. 5-25, 2013.

MARSHALL, S.; TAYLOR, J. A.; OGLESBY, R. J.; LARSON, J. W.; ERICKSON, D. J. Climate Effects of biomass burning. Environmental Software, v. 11, n. 1, p.53-58, 1996. 
MARTINS, F. S. R. V.; XAUD, H. A. M.; SANTOS, J. R.; GALVÃO, L. S. Effects of fire on above-ground forest biomass in the northern Brazilian Amazon. Journal of Tropical Ecology, v. 28, n. 6, p. 591-601, 2012.

MENDONÇA, M. J. C.; DIAZ, M. C. V.; NEPSTAD, D.; MOTTA, R. S.; ALENCAR, A.; GOMES, J. C.; ORTIZ, R. A.The economic cost of the use off ire in the Amazon.Ecological Economics, v. 49, n. 1, p. 89-105, 2004.

MIETTINEN, J.; LIEW, S. C. Comparison of multitemporal compositing methods for burnt area detection in Southeast Asia conditions. International Journal of Remote Sensing, v. 29, n. 4, p. 1075-1092, 2008.

MIEVILlE, A.; GRANIER, C.; LIOUSSE, C.; GUILlAUME, B.; MOUILlOT, F.; LAMARQUE, J.-F.; GRÉGOIRE, J.-M.; PÉTRON, G. Emissions of gases and particles from biomass burning during the 20th century using satellite data and historical reconstruction.Atmospheric Environment.v. 44, p.1469-1477, 2010.

MIRANDA, H. S.; SATO, M. N.; NASCIMENTO NETO, W.; AIRES, F. S. Fires in the cerrado, the Brazilian savanna. In: Cochrane, M. A. (Ed.). Tropical Fire Ecology: Climate Change, Land Use, and the Ecosystems Dynamics.Chichester: Springer-Praxis, 2009, p. 427-444.

MORTON, D. C.; DEFRIES, R. S.; SHIMABUKURO, Y. E.; ANDERSON, L. O.; ESPÍRITO-SANTO, F. D. B.; HANSEN, M.; CARROLL, M. Rapid Assessment of Annual Deforestation in the Brazilian Amazon Using MODIS Data. Earth Interactions, v. 9, n. 8, p. $1-23,2005$.

MORTON, D.C.; DEFRIES, R.S.; RANDERSON, J.T.; GIGLIO, L.; SCHROEDER, W.; VAN DER WERF, G.R. Agricultural intensification increases deforestation fire activity in Amazonia. Global Change Biology, v. 14, n. 10, p. 2262-2275, 2008.

MOUILlOT, F.; SCHUlTZ, M. G.; YUE, C.; CADUle, P.; TANSEY, K.; CIAIS, P.; CHUVIECO, E. Ten years of global burned area products from spaceborne remote sensingA review: Analysis of user needs and recommendations for future developments.International Journal of Applied Earth Observation and Geoinformation, v. 26, p. 64-79, 2014.

NARENDRA, P. M. A Separable Median Filter for Image Noise Smoothing. IEEE Transactions on Pattern Analysis and Machine Intelligence,v. 3, n. 1, p. 20-29, 1981.

NELSON, A.; CHOMITZ, K. M. Effectiveness of Strict vs. Multiple Use Protected Areas in Reducing Tropical Forest Fires: A Global Analysis Using Matching Methods. PLoS One, v. 6, n. 8, p. 1-15, 2011.

NEPSTAD, D. C.; SCHWARTZMAN, S.; BAMBERGER, B.; SANTILLI, M.; RAY, D.; SCHLESINGER, P.; LEFEBVRE, P.; ALENCAR, A.; PRINZ, E.; FISKE, G.; ROLLA, A. Inhibition of Amazon Deforestation and Fire by Parks and Indigenous Lands. Conservation Biology, v. 20, n. 1, p. 65-73, 2006.

NEPSTAD, D. C.; VERÍSSIMO, A.; ALENCAR, A.; NOBRE, C.; LIMA, E.; LEFEBVRE, P.; SCHLESINGER, P.; POTTER, C.; MOUTINHO, P.; MENDOZA, E.; COCHRANE, M.; BROOKS, V. Large-scale impoverishment of Amazonian forests by logging and fire. Nature, v. 398, p. 505-508, 1999. 
NEPSTAD, D., CARVAlHO, G., BARROS, A. C., ALENCAR, A., CAPOBIANCO, J. P., BISHOP, J., MOUTINHO,P., LEFEBVRE, P.; SILVA JR. U. L.; PRINS, E. Road paving, fire regime feedbacks, and the future of Amazon forests. Forest ecology and management, v. 154, n. 3, p. 395-407, 2001.

NEPSTAD, D.; LEFEBVRE, P.; LOPES DA SILVA, U.; TOMASELLA, J.; SCHLESINGER, P.; SOLORZANO, L.; MOUTINHO, P.; RAY; D.; BENITO, J.G. Amazon drought and its implications for forest flammability and tree growth: A basin-wide analysis. Global Change Biology, v. 10, n. 5, p. 704-717, 2004.

PADILLA, M.; STEHMAN, S. V.; CHUVIECO, E. Validation of the 2008 MODIS-MCD45 global burned area product using stratified random sampling. Remote Sensing of Environment, v. 144, p. 187-196, 2014.

PARRINI, F.; OWEN-SMITH, N. The importance of post-fire regrowth for sable antelope in a Southern African savanna.African Journal of Ecology, v. 48, n. 2, p. 526-543, 2010.

PEREIRA, J. M. C. Remote sensing of burned areas in tropical savannas. International Journal of Wildland Fire, v. 12, n. 4, p. 259-270, 2003.

PEREIRA, J. M. C., SA, A. C. L., SOUSA, A. M. O., SILVA, J. M. N., SANTOS, T. N., CARREIRAS, J. M. B. Spectral characterization and discrimination of burnt areas. In: E. Chuvieco (Ed.).Remote sensing of large wildfires in the European Mediterranean basin. Springer-Verlag, Berlin, 1999. p. 123-138.

PHILLIPS, O.L.; VAN DER HEIJDEN, G.; LEWIS, S.L.; LÓPEZ-GONZÁLEZ, G.; ARAGÃO, L.E.; LLOYD, J.; MALHI, Y., MONTEAGUDO, A., ALMEIDA, S., DÁVILA, E.A., AMARAL, I., ANDELMAN, S., ANDRADE, A., ARROYO, L., AYMARD, G., BAKER, T.R., BLANC, L., BONAL, D., DE OLIVEIRA, Á.C.A., CHAO, K.-J., CARDOZO, N.D., DA COSTA, L., FELDPAUSCH, T.R., FISHER, J.B., FYLLAS, N.M., FREITAS, M.A., GALBRAITH, D., GLOOR, E., HIGUCHI, N., HONORIO, E., JIMÉNEZ, E., KEELING, H., KILLEEN, T.J., LOVETT, J.C., MEIR, P., MENDOZA, C., MOREL, A., VARGAS, P.N., PATINO, S., PEH, K.S.-H., CRUZ, A.P., PRIETO, A., QUESADA, C.A., RAMÍREZ, F., RAMÍREZ, H., RUDAS, A., SALAMÃO, R., SCHWARZ, M., SILVA, J., SILVEIRA, M., FERRY SLIK, J.W., SONKÉ, B., THOMAS, A.S., STROPP, J., TAPLIN, J.R.D., VÁSQUEZ, R., VILANOVA, E. Drought-mortality relationships for tropical forests. New Phytologist, v. 187, n. 3, p. 631-646, 2010.

PIROMAL, R.A.S.; RIVERA-LOMBARDI, R.J.; SHIMABUKURO, Y.E.; FORMAGGIO, A.R.; KRUG, T. Utilização de dados MODIS para a detecção de queimadas na Amazônia. Acta Amazonica, v. 38, n. 1, p. 77-84, 2008.

PIVELLO, V. R. The Use of Fire in the Cerrado and Amazon Rainforests of Brazil: Past and Present.Fire Ecology, v. 7, n. 1, p. 24-39, 2011.

PLENIOU, M.; KOUTSIAS, N. Sensitivity of spectral reflectance values to different burn and vegetation ratios: A multi-scale approach applied in a fire affected area. ISPRS Journal of Photogrammetry and Remote Science, v. 79, p. 199-210, 2013.

QUINTANO, C.; FERNÁNDEZ-MANSO, A.; CALVO, L.; MARCOS, E.; VALBUENA, L. Land surface temperature as potential indicator of burn severity in forest Mediterranean ecosystems. International Journal of Applied Earth Observation and Geoinformation, v. 36, p. 1-12, 2015. 
QUINTANO, C.; FERNÁNDEZ-MANSO, A.; STEIN, A.; BIJKER, W. Estimation of area burned by forest fires in Mediterranean countries: A remote sensing data mining perspective. Forest Ecology and Management, v. 262, n.8, p. 1597-1607, 2011.

REDDINGTON, C.L.; BUTT, E.W.; RIDLEY, D.A.; ARTAXO, P.; MORGAN, W.T.; COE, H.; SPRACKLEN, D.V. Air quality and human health improvements from reductions in deforestation-related fire in Brazil. Nature Geoscience, v. 8, n. 10, p. 768-771, 2015.

RIBEIRO, H.; ASSUNÇÃO, J. V. Efeitos das queimadas na saúde humana. Estudos Avançados, v. 16, n. 44, p. 125-148, 2002.

RIGHI, C. A. GRAÇA, P. M. L.; CERRI, C. C.; FEIGL, B. J.; FEARNSIDE, P. M. Biomass burning in Brazil's Amazonian "arc of deforestation": Burning efficiency and charcoal formation in a fire after mechanized clearing at Feliz Natal, Mato Grosso. Forest Ecology and Management, v. 258, p. 2535-2546, 2009.

RONCHAIL, J.; COCHONNEAU, G.; MOLINIER, M.; GUYOT, J.L.; DE MIRANDA CHAVES, A.G.; GUIMARÃES, V.; DE OLIVEIRA, E. Interannual rainfall variability in the Amazon basin and sea-surface temperatures in the equatorial Pacific and the tropical Atlantic Oceans.International Journal of Climatology, v. 22, n. 13, p. 1663-1686, 2002.

ROUSE, J. W.; HAAS, R. H.; SCHELL, J. A.; DEERING, D. W.; \& HARLAN, J. C. Monitoring the vernal advancement of retrogradation of natural vegetation (Type III, Final Report). Greenbelt, MD: NASA/GSFC, p. 371, 1974.

ROY, D. P.; BOSCHETTI, L. Southern Africa Validation of the MODIS, L3JRC and GlobCarbon Burned-Area Products. IEEE Transactions on Geoscience and Remote Sensing, v. 47, n. 4, p. 1032-1044, 2009.

ROY, D. P.; BOSCHETTI, L.; JUSTICE, C. O.; JU, J. The collection 5 MODIS burned area product - Global evaluation by comparison with the MODIS active fire product. Remote Sensing of Environment, v. 112, p. 3690-3707, 2008.

ROY, D. P.; BOSCHETTI, L.; TRIGG, S. N. Remote sensing of fire severity: assessing the performance of the normalized burn ratio.IEEE Geoscience and Remote Sensing Letters,v. 3, n. 1, p. 112-116, 2006.

ROY, D.P.; JIN, Y.; LEWIS, P.E.; JUSTICE, C.O. Prototyping a global algorithm for systematic fire-affected area mapping using MODIS time series data. Remote Sensing of Environment, v. 97, p. 137-162, 2005.

ROY, D. P.; LEWIS, P. E.; JUSTICE, C. O. Burned area mapping using multi-temporal moderate spatial resolution data-a bi-directional reflectance model-based expectation approach. Remote Sensing of Environment, v.83, n. 1-2, p. 263-286, 2002.

SAKAMOTO, T.; YOKOZAWA, M.; TORITANI, H.; SHIBAYAMA, M.; ITSHITSUKA, N.; OHNO, H.A crop phenology detection method using time-series MODIS data. Remote Sensing of Environment, n. 96, p. 366-374, 2005.

SALDARRIAGA, J. C.; WEST, D. C. Holocene fires in the northern Amazon basin.Quaternary Research, v.26, n. 3, p. 358-366, 1986.

SAVITZKY, A.; GOLAY, M. J. E. Smoothing and Differentiation of Data by simplified Least Squares Procedures. Analytical Chemistry, v.36, n. 8, p. 1627-1639, 1964. 
SCHAFER, R. W. What Is a Savitzky-Golay Filter? IEEE Signal Processing Magazine, v. 28, n. 4, p. 111-117, 2011.

SCHROEDER, W.; MORISETTE, J. T.; CSISZAR, I.; GIGLIO, L.; MORTON, D.; JUSTICE, C. O. Characterizing Vegetation Fire Dynamics in Brazil through Multisatellite Data: Common Trends and Practical Issues. Earth Interactions, v. 9, n. 13, p.1-26, 2005.

SHIMABUKURO, Y. E.; DUARTE, V.; ARAI, E.; FREITAS, R. M.; LIMA, A.; VALERIANO, D. M.; BROWN, I. F.; MALDONADO, L. R. Fraction images derived from Terra Modis data for mapping burnt areas in Brazilian Amazonia. International Journal of Remote Sensing, v. 30, n. 6, p.1537-1546, 2009.

SILVESTRINI, R. A.; SOARES-FILHO, B. S.; NEPSTAD, D.; COE, M.; RODRIGUES, H.; ASSUNÇÃO, R. Simulating fire regimes in the Amazon in response to climate change and deforestation. Ecological Applications, v. 21, n. 5, p. 1573-1590, 2011.

SOARES, J. V.; BATISTA, G. T.; SHIMABUKURO, Y. E. HISTÓRICO E DESCRIÇÃO. IN: RUDORFF, B. F. T.; SHIMABUKURO, Y. E.; CEBALLOS, J. C. (Org.) O sensor MODIS e suas aplicações ambientais no Brasil.São José dos Campos: Parêntese Editora, 2007, p. 3-23.

van der WERF, G. R.; MORTON, R. S.; DEFRIES, R. S.; GIGLIO, L.; RANDERSON, J. T.; COLLATZ, G. J.; KASIBHATLA, P. S. Estimates of fire emissions from an active deforestation region in the southern Amazon based on satellite data and biogeochemical modelling. Biogeosciences, v. 6, p. 235-249, 2009.

VERAVERBEKE, S.; LHERMITTE, S.; VERSTRAETEN, W.W.; GOOSSENS, R. The temporal dimension of differenced Normalized Burn Ratio (dNBR) fire/burn severity stuydies: The case of the large 2007 Peloponnese wildfires in Greece. Remote Sensing of Environment, v. 114, p. 2548-2563, 2010.

VERBESSELT, J.; JÖNSSON, P.; LHERMITTE, S.; JONCKHEERE, I.; VAN AARDT, J.; COPPIN, P. Relating time-series of meteorological and remote sensing indices by extraction of seasonality metrics to monitor vegetation moisture dynamics. In: Chen (Org.). Signal and Image Processing for Remote Sensing, Boca Raton, FL: CRC Press/Taylor \& Francis Group, p.153-172, 2007. cap. 8.

WHITLOCK, C.; HIGUERA, P. E.; MCWETHY, D. B.; BRILES, C. E. Paleoecological Perspectives on Fire Ecology: Revisiting the Fire-Regime Concept. The Open Ecology Journal, v. 3, p. 6-23, 2010.

ZHANG, R.; QU, J. J.; LIU, Y.; HAO, X.; HUANG, C.; ZHAN, X. Detection of burned areas from mega-fires using daily and historical MODIS surface reflectance. International Journal of Remote Sensing, v. 36, n. 4, p. 1167-1187, 2015.

ZIMMERMAN, B.; PERES, C. A.; MALCOLM, J. R.; TURNER, T. Conservation and development alliances with the Kayapó of south-eastern Amazonia, a tropical forest indigenous people. Environmental Conservation, v. 28, n. 1, p. 10-22, 2001. 